\title{
REGENERATION AND FUNCTIONAL RECONNECTION OF AN IDENTIFIED VERTEBRATE CENTRAL NEURON ${ }^{1}$
}

\author{
MATT T. LEE ${ }^{2}$
}

\author{
Biology Department, University of California, San Diego, La Jolla, California 92093
}

Received April 7, 1982; Revised June 1, 1982; Accepted June 2, 1982

\begin{abstract}
I have examined the axonal regeneration of a pair of identified central neurons, the Mauthner (M) neurons, in Xenopus laevis tadpoles. Lucifer Yellow injections reveal regenerative sprouts arising from the proximal stumps of the $M$ axons within a few days after axotomy; some of these can cross the lesion within 1 week. Many specimens examined at later times (up to 21 weeks) have processes that extend more than $2 \mathrm{~mm}$ (equivalent to 5 to 10 spinal segments) beyond the lesion. $M$ axons which have regenerated caudal to the lesion can re-establish functional synaptic contacts with their normal targets, spinal motor neurons. Functional reconnection has been demonstrated as early as 9 days after axotomy and as far as 10 segments caudal to the lesion. In most of the specimens tested, the regenerating $M$ axons appear to exhibit the same degree of specificity for appropriate postsynaptic targets as normal, untransected $M$ axons. $M$ axons retain the ability to regenerate throughout the range of stages included in this study. The results provide evidence that a return of normal function in the transected vertebrate spinal cord can be mediated by the reconnection of a regenerating neuron with its normal targets.
\end{abstract}

The failure of nerve fibers within the mammalian CNS to regenerate after transection is a problem of great medical significance. In general, the growth of fibers across a lesion is limited to a few processes that extend only a short distance beyond the site of damage (for reviews, see Puchala and Windle, 1977; Kiernan, 1979), although some reports have indicated that the regenerative capacities of neurons may be greater in neonates than in adults (Kalil and Reh, 1979; Björklund and Stenevi, 1979).

This type of plasticity is found to a much larger extent in the central nervous systems of nonmammalian vertebrates. Transection of the spinal cord is followed by both the presence of axons spanning the lesion and behavioral recovery in lampreys (Hibbard, 1963; Rovainen, 1976; Selzer, 1978; Wood and Cohen, 1981), teleosts (Hooker, 1932; Tuge and Hanzawa, 1937; Bernstein and Gelderd, 1970), urodele amphibia (Holtzer, 1952; Piatt, 1955), and larval anuran amphibia (Hooker, 1925; Sims, 1962;

\footnotetext{
' This work was supported by National Institutes of Health predoctoral training grants and by grants to $N$. Spitzer from the National Institutes of Health (NS 15928) and the Office of Naval Research (N00014-79-C-0748). I thank N. Spitzer for advice and encouragement during the execution of this research, N. Spitzer and J. Bixby for criticism of the manuscript, A. Selverston for the use of the facilities in his laboratory, and W. Stewart for the gift of Lucifer Yellow.

${ }^{2}$ Present address: Department of Psychology, Building 420, Jordan Hall, Stanford University, Stanford, CA 94305.
}

Michel and Reier, 1979). The inability of the spinal cord to regenerate in adult anurans (Piatt and Piatt, 1958) suggests an age-dependent decline in the regenerative capacity of these animals as well. However, the functional relationship between the fibers that grow across the lesion and the observed behavioral recovery has not been demonstrated.

Moreover, in most investigations of vertebrate central regeneration, it is not certain that the phenomenon being studied is, in fact, the regeneration of axons that were severed by the surgical manipulation. The anatomical and behavioral appearance of regeneration could be due to collateral sprouting of intact fibers that were spared by the lesion. Another possible alternative is that the axons found crossing a transection may have arisen from neurons that began differentiating after the operation was performed; the presence of these axons would represent initial outgrowth rather than regrowth after axotomy (Sechzer, 1974). These complications have been inherent in most studies of vertebrate CNS regeneration, which have almost always dealt with the responses of large populations of neurons that are not individually identifiable.

At present, there are only a few individually identified neurons known in the vertebrate CNS, the most prominent of which are the Müller cells of lampreys (Rovainen, $1979)$ and the Mauthner (M) cells of lampreys, teleosts, and amphibians (Faber and Korn, 1978). The M cells are by far the better studied of these. 
M cells are paired neurons whose somata are situated in the medulla at the level of the 8 th nerve. Most of the information about the morphology and physiology of these neurons has been obtained from a few species of teleosts (Faber and Korn, 1978). In these species, the $M$ cell receives synaptic input from the sacculus, the lateral line, and many other sources. Output occurs via a large axon that courses medially from the soma, crosses the midline, and runs caudally in the ventral spinal cord. Activation of the $M$ neuron directly excites motor neurons bilaterally in the medulla and ipsilaterally in the spinal cord and can initiate a fast startle response that probably is used in predator avoidance. Many of these properties are shared by $\mathbf{M}$ cells in other species.

Regeneration of $M$ axons has been reported following spinal lesions in embryonic and larval urodeles (Stefanelli, 1951; Baffoni, 1952; Holtzer, 1952; Piatt, 1955), larval lampreys (Rovainen, 1976; Selzer, 1978; Wood and Cohen, 1981), and adult goldfish (Zottoli, 1981). Previous studies have noted a lack of $\mathbf{M}$ axon regeneration in larval anurans (Stefanelli, 1951; Baffoni, 1952; Sims, 1962).

Although the ability of $\mathrm{M}$ axons to regenerate has been demonstrated in several species, only in the lamprey is there evidence that the axons can re-form synapses below the lesion (Wood and Cohen, 1981); however, this evidence is ultrastructural, and the identity of the postsynaptic cells is unknown. No physiological experiments have been reported in any species dealing with the question of whether regenerating $\mathbf{M}$ axons can re-establish functional synapses with their normal postsynaptic targets.

This paper describes experiments which were conducted to examine the regeneration of $M$ axons in larvae (tadpoles) of the African clawed frog, Xenopus laevis. The only previous study on this subject in Xenopus indicated that the $M$ axons do not regrow after spinal transections in tadpoles at a single late stage in development (Sims, 1962). Because of the correlation between age and regenerative capacity mentioned above, I hypothesized at the outset of this work that Xenopus M axons might be capable of regeneration if transected during early developmental stages.

The present work addresses four main questions: $(a)$ Can $\mathbf{M}$ cells regenerate their severed axons? (b) Can axotomized $M$ cells re-form functional synapses on their normal targets below the lesion? (c) Is synaptic reconnection specific for normal $M$ cell targets? $(d)$ What is the stage dependence of $\mathrm{M}$ axon regeneration?

None of the earlier studies of Xenopus M cell anatomy have described the morphology of the axon with the detail presently available with fluorescent dye injection, and previous reports on the physiology of $\mathrm{M}$ cells in this species are lacking. Consequently, it was necessary to investigate first the anatomy and physiology of $\mathbf{M}$ cells in normal tadpoles in order to provide a standard of comparison for the results obtained from tadpoles with spinal lesions. The first part of this paper describes those aspects of $M$ cells in normal tadpoles that are essential for this comparison; the second part presents the results of experiments addressing the four questions posed above.
A preliminary account of some of these results has appeared (Lee, 1980).

\section{Materials and Methods}

Raising of tadpoles. Xenopus laevis tadpoles were raised from eggs laid in the laboratory by paired adult frogs which had been injected previously with human chorionic gonadotropin (Sigma) to induce breeding (Gurdon, 1967). The tadpoles were kept in aquaria containing $10 \%$ Holtfreter's solution at room temperature (19 to $23^{\circ} \mathrm{C}$ ).

Staging and dissections. Tadpoles were staged according to the external criteria of Nieuwkoop and Faber (1956).

For most experiments, the brain and spinal cord were completely isolated from the tadpole except for a small amount of cartilage or muscle at the rostral and caudal ends, by which the preparation was pinned out. The proximal segments of the ventral roots were left attached to the spinal cord so that activity within the roots could be monitored with suction electrodes. Ventral roots were numbered according to the scheme of Gaupp (1896).

Some experiments required the isolation of part of the axial (swimming) musculature and the developing hindlimbs along with the brain and spinal cord. In these cases, the ventral and dorsal surfaces of the spinal cord were exposed by removing the notochord and the dorsal part of the axial musculature. This procedure left the spinal cord connected via the intact ventral roots to a fillet of axial muscle and a hindlimb on each side. The hindlimbs were dissected to expose the limb nerves, which were identified according to Gaupp (1896).

General experimental procedure. The preparation was pinned, ventral side up, in a pool of Ringer's solution in an experimental chamber that consisted of a plastic tissue culture dish with a glass coverslip bottom. This chamber was mounted on the stage of a compound microscope with Nomarski differential interference contrast optics and $\times 12.5$ oculars. Microelectrode penetrations were made while viewing through a $\times 40$ water immersion objective; suction electrodes were positioned with stagemounted manipulators under $\mathrm{a} \times 6.3$ dry objective.

All experiments were conducted at room temperature. Most were done without changing the bathing solution in the chamber. Some experiments on preparations from older tadpoles were done during continuous perfusion of the preparation with aerated Ringer's solution.

Physiology. Intracellular impalements were made with microelectrodes having resistances of approximately 60 to 100 megohms when filled with $3 \mathrm{M} \mathrm{KCl}$. Prior to impalement, their tips were beveled until the resistance had decreased to approximately 30 megohms. Some impalements were made with electrodes filled with $3 \mathrm{M} \mathrm{KAc}$ and beveled to the same final resistance. A single electrode was used for both stimulating and recording intracellularly. $M$ axons were impaled in the spinal cord or caudal medulla by approaching the axon with the microelectrode parallel to it, positioning the electrode until its tip could be visualized within the axon sheath, and then tapping the micromanipulator or the table top until a drop in potential was observed. Axons of spinal motor neurons were impaled in the same fashion. Extracellular 
stimulation and recording from ventral roots and hindlimb nerves were accomplished with suction electrodes.

Conventional techniques were used for stimulation and for amplification and display of recorded signals. Photographs of stored oscillographic traces were made with a Grass C4R camera on Kodak Linagraph paper.

Anatomy. The fluorescent dye, Lucifer Yellow, was injected into $M$ axons and motor axons with microelectrodes beveled to a resistance of 150 to 200 megohms. These electrodes contained either $(a)$ a $5 \%(\mathrm{w} / \mathrm{v})$ aqueous solution of Lucifer Yellow in the shank and distal 1 to 2 $\mathrm{mm}$ of the barrel, connected to the electrometer probe via a chlorided silver wire, or $(b)$ the same amount and concentration of Lucifer Yellow, followed by a volume of $3 \mathrm{~m} \mathrm{LiCl} \mathrm{sufficient} \mathrm{to} \mathrm{fill} \mathrm{the} \mathrm{remainder} \mathrm{of} \mathrm{the} \mathrm{barrel.} \mathrm{Dye}$ was ejected from the electrode by passing negative current through the electrode for 5 to $15 \mathrm{~min}$ ( 1 to $12 \mathrm{nA}$, DC or 500 -msec pulses at $1 \mathrm{~Hz}$ ). Sometimes the dye was given an additional 15 to $30 \mathrm{~min}$ to diffuse more completely throughout the cell after injection.

Each preparation was transferred to another chamber and fixed by immersion in $4 \%$ paraformaldehyde in $0.1 \mathrm{M}$ phosphate buffer ( $\mathrm{pH} \sim 7.4$ ) for 1 to $3 \mathrm{hr}$ at room temperature. Following dehydration in ethanol, the specimens were cleared in methyl benzoate or methyl salicylate and viewed in whole mount on a depression slide or in a Sylgard-coated plastic dish with a glass coverslip bottom.

Most specimens were examined and photographed through a Zeiss Photomicroscope with a 200-W mercury lamp, using fluorescein isothiocyanate and BG3 or BG12 exciter filters, and a $500-\mathrm{nm}$ barrier filter. For some specimens, illumination was provided by a $100-\mathrm{W}$ tungsten lamp, with other conditions remaining the same. Photographs were made with high contrast, panchromatic, black-and-white film (Kodak 5069 or 2415).

Spinal cord lesions. Tadpoles were anesthetized by incubation in one of the following: $(a)$ ice cold $10 \%$ Holtfreter's solution, (b) $10 \%$ Holtfreter's solution at room temperature containing 100 to $200 \mathrm{mg}$ /liter of tricaine methanesulfonate (TMS; Sigma), or $(c)$ ice cold 10\% Holtfreter's solution containing TMS. Each animal was placed in a Sylgard-covered plastic dish containing one of these solutions, staged, and then restrained with pins stuck into the Sylgard, surrounding but not penetrating the tadpole's body.

Most lesions consisted of complete spinal transections. These were performed under a dissecting microscope by one of three methods.

(a) Young tadpoles (generally before stage 46) were positioned with their left or right side up; a small segment of razor blade was used to cut through the dorsal half of the animal, severing the spinal cord and the dorsal notochord. These cuts were made at the level of the caudal end of the gut, corresponding roughly to the 4th to 10 th spinal segment, depending upon the stage.

(b) Intermediate tadpoles (stages 46 to 49 ) were positioned with their dorsal surface up; the dorsal fin was cut, and the myotomes were peeled back to expose the spinal cord in a small region, where it was severed with a pair of tungsten hooks. These transections were made at the level of the 3rd to 5th myotome; since the ventral roots run caudally for about 2 spinal segments between the spinal cord and the myotomes that they innervate, this put the lesion near the level at which the 5th to 7 th ventral roots exit the spinal cord.

(c) Old tadpoles (stages 50 to 56) were cut at the same level and in the same manner as those of intermediate stages, except that the spinal transection was performed with iridectomy scissors.

Some tadpoles received spinal crushes (spinal cord pinched but not severed) or hemisections (one side severed) instead of complete transections. These operations were performed when the specimen was to be examined at short postoperative times, since they permitted the two ends of the spinal cord to remain attached after the cord had been isolated by dissection.

For complete transections, the effectiveness of the lesion in severing the $M$ axons was confirmed at the time of the operation by observing the passage of tungsten hooks between the two ends of the spinal cord. The effectiveness of crushes and hemisections was determined by subsequent examination of the dye-filled $\mathbf{M}$ axons; 8 of these preparations were excluded from consideration because the lesion appeared to have left the $M$ axons undamaged (that is, the $M$ axons had a normal morphology caudal to the lesion).

Postoperative procedures. Following the operation, tadpoles were placed in 20 to $100 \mathrm{ml}$ of $10 \%$ Holtfreter's solution in individual containers at room temperature. The fluid in the containers was changed about once a week and was aerated for tadpoles that received lesions at stages 50 to 56 . At various postoperative times, tadpoles were chosen and dissected for physiological and/or anatomical study. In some of the older tadpoles, the isolated spinal cord was so thick that the $M$ axons could not be seen. In order to improve visibility in these preparations, the dorsal half of the caudal medulla/rostral spinal cord was cut away, between the 10th cranial nerve and the 3rd or 4th spinal nerve root. Forceps and electrolytically sharpened tungsten hooks then were used to strip axons from the ventral surface of the CNS in this region until the $M$ axons became visible.

Composition of solutions. The composition of $10 \%$ Holtfreter's solution was (in millimolar concentrations): $\mathrm{NaCl}, 6.0 ; \mathrm{KCl}, 0.07 ; \mathrm{CaCl}_{2}, 0.09 ; \mathrm{NaHCO}_{3}, 0.2$. Normal Ringer's solution had the following composition for most of the experiments (in millimolar concentrations): $\mathrm{NaCl}$, 125; $\mathrm{CaCl}_{2}, 1.8 ; \mathrm{KCl}, 3$; HEPES, 5 (pH 7.4). Ringer's solution containing $10 \mathrm{~mm} \mathrm{CaCl} 2$ was used in early experiments. Glucose $(5 \mathrm{~mm})$ was added to the normal Ringer's solution to increase the viability of preparations from older tadpoles. For preparations which included axial muscle, $d$-tubocurarine chloride (10 to $20 \mathrm{mg} / \mathrm{liter}$; Sigma), was included to prevent muscular contractions. Modifications of normal Ringer's solution for particular experiments are indicated in the figure legends.

\section{Results}

\section{$M$ cells in normal tadpoles}

Anatomy. By stage 47, the $\mathrm{M}$ axons can be seen very clearly in the isolated brain and spinal cord of a Xenopus tadpole, when viewed from the ventral surface with No- 
marski or bright-field optics (Fig. 1, $A$ and $B$ ). Prior to this stage, they are not recognizable by this method, probably due to their small diameter and light myelination. 'The $M$ axons remain visible up to the latest stage examined (stage 57). Although the somata are not discernible under these conditions, the axons can be traced from their origin in the medulla to spinal segment 15. These axons are the largest in the spinal cord, having a diameter in the rostral spinal cord of approximately $8 \mu \mathrm{m}$ at stage 47 and $15 \mu \mathrm{m}$ at stage 57 . They arise from paired somata located at the level of the 8th cranial nerve in the medulla and, after decussating in the medulla, run caudally in the spinal cord, one on each side of the midline. Within the spinal cord, they are situated medially, close to the ventral surface (see also Fig. 2). These features are characteristic of $M$ axons in other species (Faber and Korn, 1978) and allow the $M$ axons to be distinguished unequivocally from all other axons.

The heavy myelination of the $\mathbf{M}$ axons can be demonstrated by examining the preparation between crossed polarizing filters; with these optics, the birefringence of myelin makes the $\mathrm{M}$ axons distinct (Fig. 1C). This procedure also clearly reveals nodes in the myelin sheaths of the $\mathrm{M}$ axons. These nodes are spaced irregularly, with the internodal length varying from approximately 100 to $400 \mu \mathrm{m}$.

Lucifer Yellow, injected into an $M$ axon, spreads throughout the cell in both directions. After a good injection, the soma and dendrites fluoresce brightly (Fig. $2 A)$. In some preparations, usually from tadpoles at older stages, the dye stops abruptly at the initial segment, where the axon is constricted, leaving the soma unfilled. Contralateral to the soma, the axon sends out numerous collaterals in the medulla (Fig. 2A) and spinal cord (Fig. $2, B$ and $C$ ). Most of the collaterals spread dorsolaterally and branch extensively within the ventral half of the spinal cord (Fig. 2C) and medulla, up to a level a few hundred micrometers rostral to the 8th nerve; some of them arborize in the region of the other M soma. In the spinal cord, these processes reach about half of the distance to the lateral margin of the cord. A few collaterals are directed medially in the spinal cord, going up to or just slightly past the midline. Occasionally, the dye fills a process that leaves the axon in the medulla and extends as far rostrally as the forebrain (not shown in Fig. 2). Its failure to fill with dye in all preparations may have been due to blockage of dye spread at a constriction (as at the initial segment) or to the absence of this collateral in most individuals.

Most of the axon collaterals can be seen to fan out from their points of origin in the nodal regions of the main axon trunk. Some of them run very close to the main axon for $100 \mu \mathrm{m}$ or more before turning dorsolaterally and branching (Fig. $2 C$ ).
Axons of motor neurons are also visible in the isolated spinal cord (Fig. 1, $B$ and $C$ ). These fibers run along the ventral surface of the cord, oblique to the $M$ axons, and can be followed out of the ventral roots to their terminations in axial or limb muscle. Some of them come to the surface of the spinal cord just medial to one of the $M$ axons; they appear to bend around the $M$ axon, passing very close to its ventral side, before exiting the cord in one of the roots. At least some of these axons belong to motor neurons that receive excitatory synaptic input from the ipsilateral $\mathrm{M}$ axon (see below).

$M$ cell input to spinal motor neurons. The results described in this section were obtained from experiments performed on tadpoles at stages 49 to 57 . Although the $M$ axons can be impaled as early as stage 47 , the ventral roots are too poorly developed prior to stage 49 to permit satisfactory extracellular recordings.

$M$ axons impaled in the spinal cord typically have resting potentials of 70 to $90 \mathrm{mV}$. The impalements are generally quite stable, lasting for several hours in some cases. Brief $(\sim 1-\mathrm{msec})$ current pulses injected into an $M$ axon elicit action potentials with a maximum amplitude of about $120 \mathrm{mV}$. Spike amplitudes are often much smaller than this, presumably because the axon has been damaged and made inexcitable in the region of the electrode penetration, and the action potential has been generated at some distant, undamaged site on the axon.

$\mathrm{M}$ cell spikes are followed within $2 \mathrm{msec}$ by compound action potentials (CAPs) recorded with suction electrodes on ipsilateral ventral roots (VRs; Fig. 3A). VRs contralateral to the stimulated $\mathrm{M}$ axon usually do not display these fast CAPs, although later occurring activity may be evoked in both ipsilateral and contralateral VRs by spikes in an $\mathrm{M}$ axon (Fig. $3, A$ and $C$ ). In rare instances, fast CAPs are recorded in contralateral VRs, but these are always much smaller than those seen ipsilaterally, suggesting that only a small number of axons are involved.

Simultaneous impalements of $\mathbf{M}$ axons and ipsilateral motor axons reveal depolarizing postsynaptic potentials in the motor axons, which follow $M$ cell spikes with a latency of $1 \mathrm{msec}$ or less (Fig. $3 B$ ); the brief latency is indicative of a monosynaptic connection between the $M$ axon and the impaled motor axons. These synaptic potentials are sometimes capable of bringing the motor neuron to threshold, and small spikes can be detected by the recording electrode in the motor axon (Fig. $3 B$ ). The latency between the $\mathbf{M}$ cell spike and the action potential recorded intracellularly in the motor axon is sufficient to account for most or all of the latency associated with the fast CAPs recorded extracellularly from the VRs. Therefore, it is likely that these fast CAPs in ipsilateral VRs are evidence of monosynaptic excitation of motor neurons by the $\mathrm{M}$ axon.

Figure 1. Normal M axons in live, dissected preparations. A, Part of the brain and spinal cord of a normal tadpole, stage 49, viewed with bright-field optics. The arrow denotes the decussation of the left $\left(M_{L}\right)$ and right $\left(M_{R}\right)$ Mauthner axons. $n$.VIII, 8th cranial nerve. $B$, Part of the spinal cord of another preparation, stage 51, including spinal segments 11 and 12 , viewed with brightfield optics. $V R$, ventral root. $C$, Same region as in $B$, viewed between crossed polarizing filters. The arrows in $B$ and $C$ indicate two of the nodes in the $\mathrm{M}$ axon myelin sheath. Calibration bars, $200 \mu \mathrm{m}$. In this and all succeeding anatomical figures, each preparation is viewed in whole mount from the ventral surface, with its rostral end pointing to the left side of the page, unless indicated otherwise. 

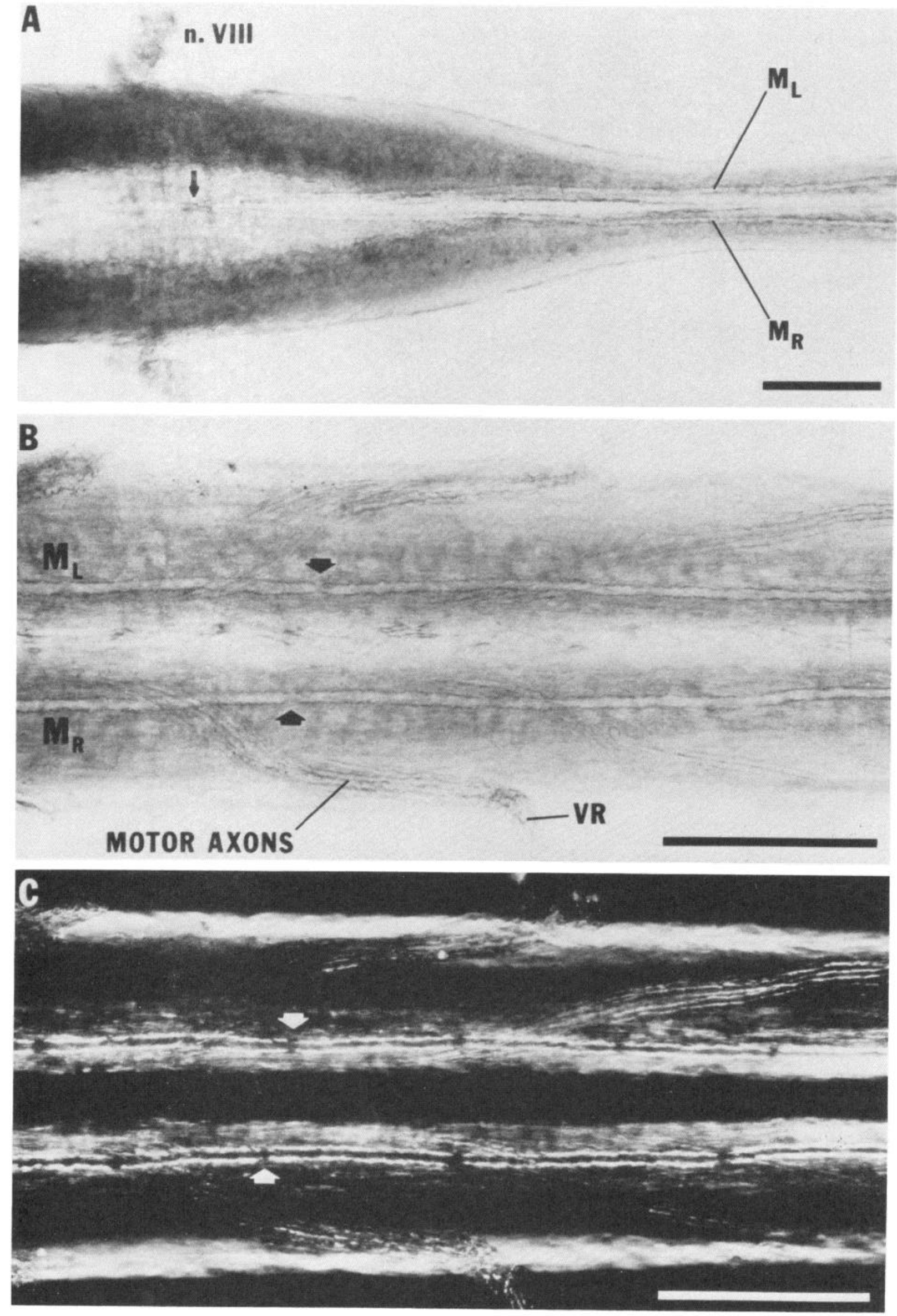

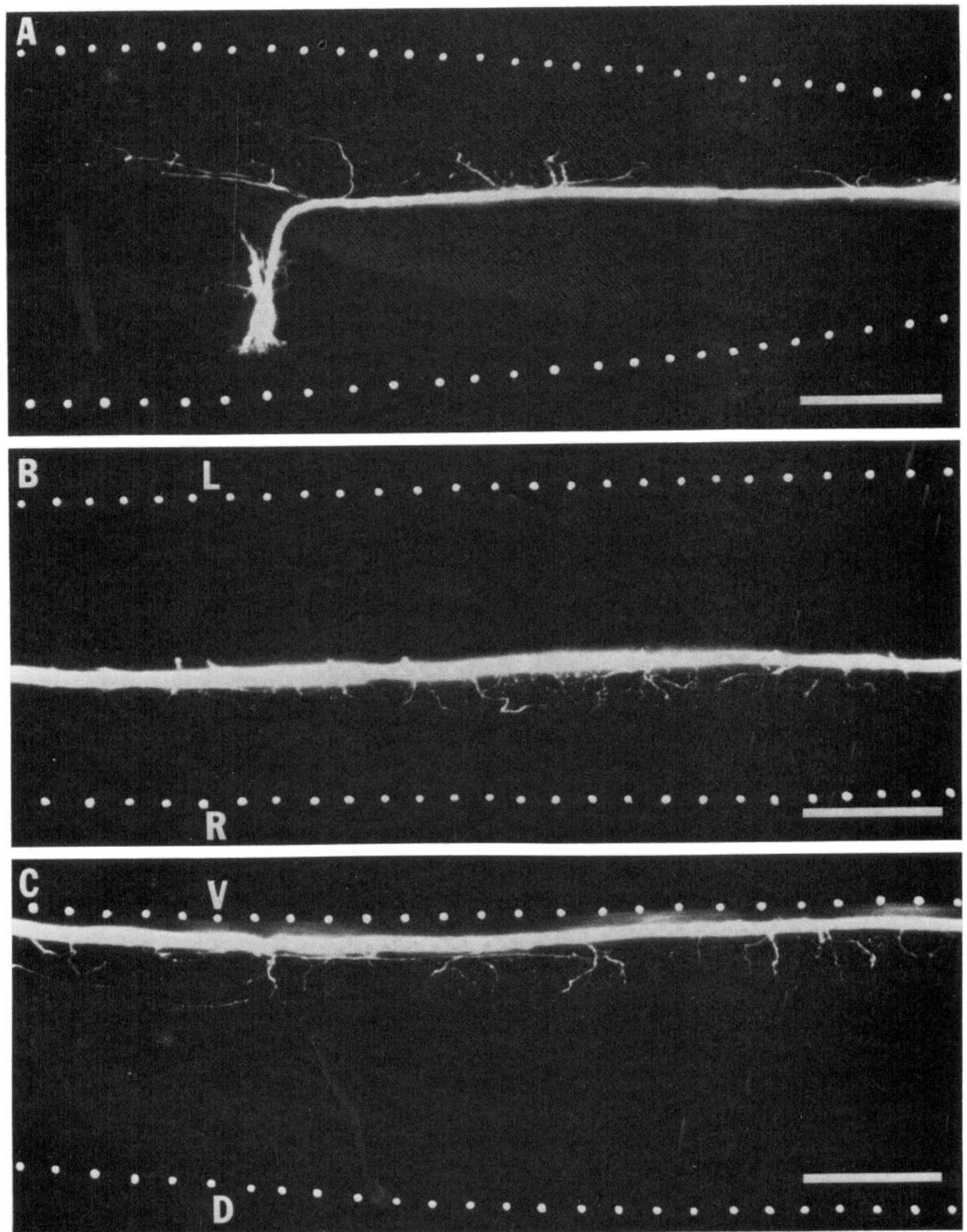

Figure 2. Normal M cells filled with Lucifer Yellow. A, Morphology of an M cell soma and axon collaterals in the medulla of a stage 50/51 tadpole. The left $\mathrm{M}$ axon was injected. $B$, The right $\mathrm{M}$ axon in the rostral part of the spinal cord of another tadpole, stage 50. $R$ and $L$ indicate the right and left sides of the cord, respectively. $C$, Another preparation, also stage 50 . The rostral spinal cord is viewed from the right side to show the dorsoventral extent of collateral branching. The right $M$ axon was injected. $D$ and $V$ mark the dorsal and ventral margins of the cord, respectively. The borders of the medulla and spinal cord are indicated by the dotted lines in this and the following figures. Calibration bars: $A, 200 \mu \mathrm{m} ; B$ and $C, 100 \mu \mathrm{m}$. 
A
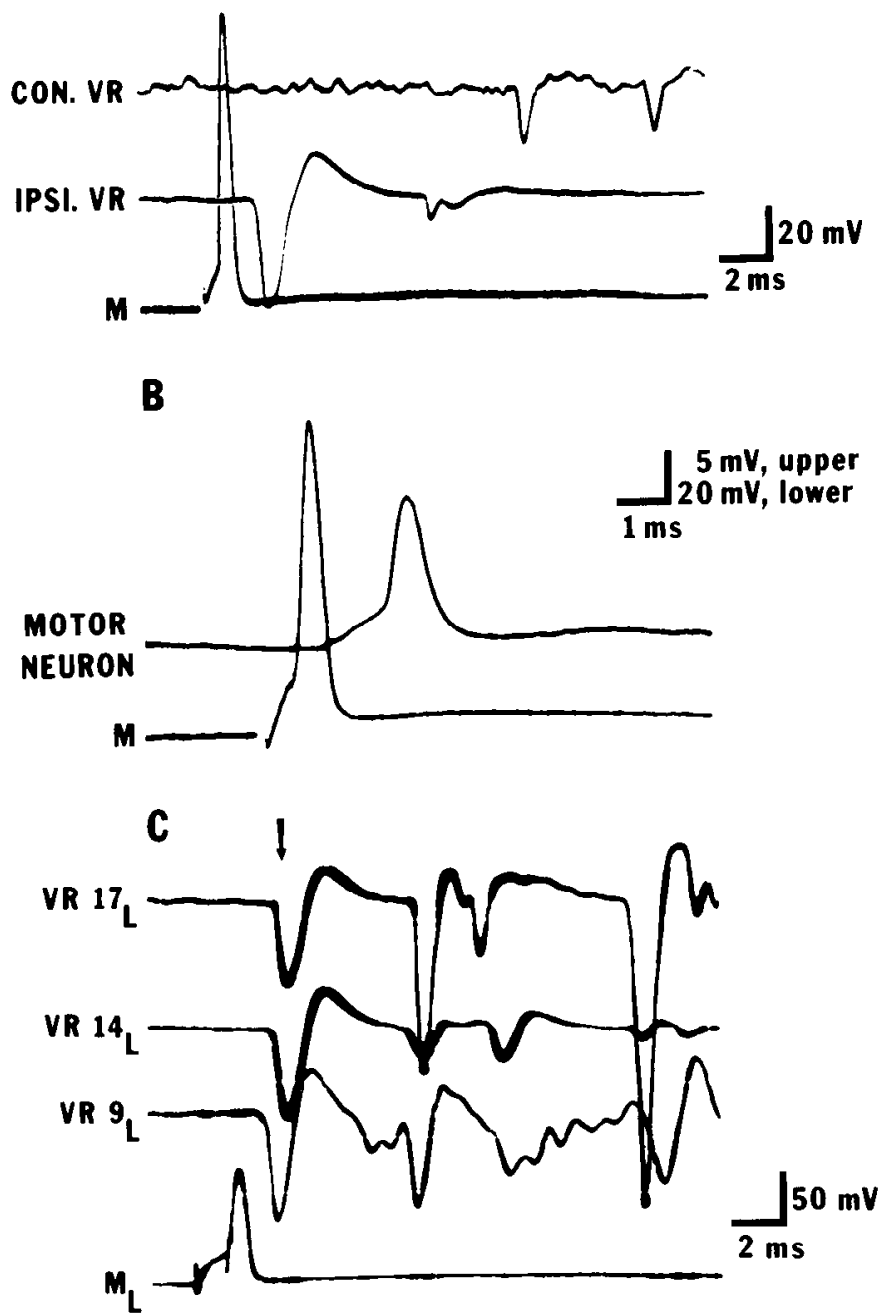

Figure 3. Basic features of $\mathbf{M}$ cell input to spinal motor neurons in normal tadpoles. $A$, Current injected into an $\mathrm{M}$ axon with an intracellular electrode produces a spike in the $M$ axon (bottom trace), followed after $2 \mathrm{msec}$ by a compound action potential (CAP) recorded with a suction electrode on the cut end of a ventral root ( $V R)$ ipsilateral to the $\mathrm{M}$ axon (middle trace). No CAP of comparable latency is present in the suction electrode record from the contralateral VR of the same segment (top trace). The recordings are from a stage 51 tadpole. $B$, Intracellularly elicited $M$ spike (bottom trace) evokes a postsynaptic potential and a spike in an ipsilateral motor neuron, recorded with an intracellular microelectrode in the motor axon (top trace). The distance between the two microelectrodes was less than $400 \mu \mathrm{m}$. The recordings are from a stage 51 tadpole. Ringer's solution contained $10 \mathrm{~mm} \mathrm{Ca}{ }^{2+}$. C, Intracellular recording from the left $M$ axon (bottom trace) and extracellular recordings from the left VRs of segments 9, 14, and 17 (top three traces). An M spike produces fast CAPs in all three VRs (at arrow). The recordings are from a stage 54/55 tadpole. In this and all physiological figures, the vertical calibrations refer only to the intracellular traces. An active circuit was used to increase the oscilloscope beam intensity during rapidly rising or falling signals, in order to compensate for the otherwise faint oscillographic storage of these signals. 'The effect of this circuit is seen as a thickening of the traces in some of the figures.

The $\mathrm{M}$ cells appear to provide monosynaptic input to motor neurons along most of the length of the spinal cord (Fig. $3 \mathrm{C}$ ). In different preparations, fast CAPs have been recorded in every spinal segment from 7 to 21 , inclusive (segments rostral to 7 and caudal to 21 were not tested). However, a rostrocaudal increase in fast CAP latency is not usually apparent; in fact, fast CAPs from caudal VRs may even precede those from rostral VRs. The most likely reason for this is that the time required for propagation of a spike down the $\mathrm{M}$ axon (approximately 0.04 $\mathrm{msec} / \mathrm{segment}$; M. T. Lee, unpublished observations) is a small fraction of the total latency of a fast CAP. The latency of fast CAPs probably is affected more by how close to threshold the motor neurons in each segment are at the instant they receive excitation from the $M$ axon (see below).

In any given preparation, fast CAPs may not be recorded in every VR tested following every ipsilateral M axon spike. Some VRs show no sign of $M$ cell input, whereas others produce fast CAPs after every $M$ axon spike; still others respond only occasionally with fast CAPs. While some of this variability could be due to damage suffered locally by particular segments of the spinal cord during dissection, much of it seems to be due to the relative timing of $\mathrm{M}$ cell input and other excitatory input received by motor neurons in each segment. When the $\mathrm{M}$ axon is stimulated during an episode of spontaneously occurring activity recorded in the VRs, the fast CAPs in ipsilateral VRs are generally much larger than those seen during the "quiet" periods between such episodes. Occasionally, this procedure has even succeeded in revealing fast CAPs in VRs which gave no indication of $M$ cell input when the $M$ axon was stimulated during quiet periods. CAPs eliciled during episodes of spontaneous activity also have slightly reduced latencies, in some cases. Therefore, though the occurrence of a fast CAP in an ipsilateral VR provides evidence for a monosynaptic connection between the $\mathrm{M}$ axon and motor neurons of that segment, the failure to observe a fast CAP in a particular VR does not imply the absence of direct $M$ cell input.

Tests for $M$ cell input to hindlimb motor neurons. Previous investigators have described two classes of motor neurons in the amphibian spinal cord: primary motor neurons, which appear early in development and innervate the axial musculature, and secondary or ventral horn motor neurons, which develop later and supply the muscles of the limbs (Youngstrom, 1940; Hughes, 1959). In anurans, axons of ventral horn motor neurons innervating the forelimb exit the spinal cord via the brachial VRs, 2, 3, and 4; those innervating the hindlimb exit via the lumbar VRs, 8, 9, and 10 (Gaupp, 1896). Axons of primary motor neurons leave the spinal cord in all of the VRs. The presence of $M$ cell-evoked fast CAPs in VRs containing no ventral horn motor neurons (see above) indicates that the $\mathrm{M}$ cell provides input to primary motor neurons. Experiments were performed to determine whether the $\mathrm{M}$ cell also synapses directly upon ventral horn motor neurons. Only the ventral horn motor neurons of the lumbar segments were studied in these experiments, since the relatively large size of the hindlimb facilitates dissection of the limb nerves.

In Xenopus tadpoles, primary and ventral horn motor neurons do not exit the spinal cord in separate fascicles (M. T. Lee, unpublished observations) as they do in Rana (Taylor, 1943). Therefore, the possibility of $\mathrm{M}$ cell input to ventral horn motor neurons of the hindlimb was examined by recording with suction electrodes on the cut 
ends of the tibial and peroneal nerves. These two nerves provide all of the motor innervation to the muscles of the lower leg and foot and are the easiest of the hindlimb nerves to identify and dissect at the stages used (54/55 through 57). Other suction electrodes were placed en passant on VRs 9 and 10, close to the spinal cord.

The experiments consisted of stimulating one of the $M$ axons and measuring the latency between the fast CAP in VR 9 or 10 and the first spikes (if any) in the two limb nerves. If any tibial or peroneal motor neurons receive direct input from the $M$ axon, their spikes should comprise part of the VR fast CAP, and the time required for conduction of those spikes to the limb nerves should equal the measured latency. The conduction time was assessed by stimulating the VRs with the en passant electrodes and recording from the limb nerves.

Results from a typical experiment are shown in Figure 4. In this example, an action potential in the left $M$ axon, evoked during an episode of spontaneous activity, produced a fast CAP in left VR 10 (Fig. $4 A$ ). The first spikes in the left tibial and peroneal nerves followed the fast CAP after 6 to $7 \mathrm{msec}$ (represented by $t_{1}$ ). This latency is much longer than the conduction time of the fastest tibial and peroneal axons ( 1.5 to 2 msec; $t_{2}$ in Fig. $4 C$ ), but it is comparable to the conduction time of the slowest axons ( 7 to $8 \mathrm{msec}$; $t_{3}$ in Fig. $4 C$ ). When the $\mathrm{M}$ axon was fired during a quiet period between episodes of spontaneous activity (Fig. $4 B$ ), $t_{1}$ increased to more than 14 msec for both limb nerves.

This type of experiment was performed on a total of $21 \mathrm{M}$ axons in 16 preparations, for 34 of the 42 tibial and peroneal nerves ipsilateral to those $\mathbf{M}$ axons. In most preparations, $t_{1}$ varied considerably, depending upon the relative timing of the $\mathbf{M}$ action potential and spontaneous activity in the preparation. Using the minimum value for $t_{1}$ obtained after repeated stimulation of each $\mathrm{M}$ axon, for all 34 nerves, $t_{1}$ was longer than $t_{2}$, but for only 3 of the 34 was $t_{1}$ longer than $t_{3}$. These data indicate that the $\mathrm{M}$ axon does not synapse directly upon tibial or peroneal motor neurons with the fastest conducting axons. It is possible that the $M$ axon does synapse upon tibial or peroneal motor neurons with slower conducting axons or that fast motor neurons are activated only polysynaptically by the $\mathrm{M}$ axon.

\section{$M$ cells in tadpoles with spinal cord lesions}

Postoperative survival and development of tadpoles. A total of 230 tadpoles, stages 39 to 56 , received complete or partial spinal cord lesions. Of these, 112 died before they could be studied. The remaining 118 tadpoles were sacrificed at postoperative times ranging from $0 \mathrm{hr}$ (immediately after making the lesion) to 21 weeks. The results described in this paper were obtained from observations on 93 of these. The other 25 are not included in this description for one or more of the following reasons: (a) the operation did not sever the $\mathbf{M}$ axons, $(b)$ the preparation was damaged during its dissection, $(c)$ the $M$ axons were not visible, or $(d)$ the $M$ axons could not be impaled successfully.

The development of those tadpoles that survived until the time of sacrifice was retarded markedly compared to the developmental timetable established by Nieuwkoop and Faber (1956). It is unlikely that their slowed development was due to the effects of the operation, since normal tadpoles raised under the same conditions developed at roughly the same rate. Much of this retardation may have been caused by the small amount of space provided for the tadpoles in their individual containers.

Short term responses of $M$ axons to transection. During the first 1 to 2 days following a spinal lesion, Lucifer Yellow, injected into an $\mathrm{M}$ axon rostral to the lesion, fills the proximal part of the cell, but the spread of dye stops
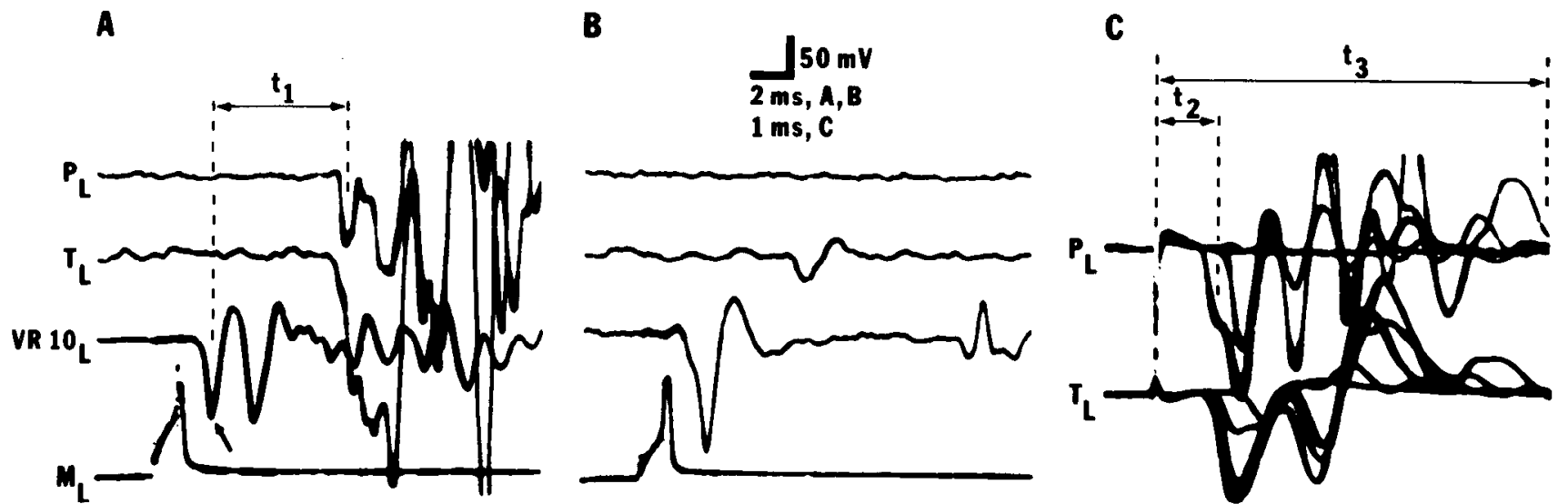

Figure 4. Tests of $\mathrm{M}$ cell input to hindlimb motor neurons in normal tadpoles. $A, B$, and $C$ were taken from the same preparation at stage 57 . Ringer's solution contained $5 \mathrm{~mm}$ glucose and $20 \mathrm{mg} /$ liter of $d$-tubocurarine chloride. $A$ and $B$, Intracellular recordings from the left $\mathrm{M}$ axon $\left(M_{L}\right)$ and extracellular recordings from left VR 10 (VR $10_{L}$; en passant) and from the cut ends of the left tibial $\left(T_{L}\right)$ and peroneal $\left(P_{L}\right)$ nerves. In $A$, current injected during an episode of spontaneous activity produces a spike in the $\mathrm{M}$ axon, which is followed by a fast CAP in $V R 10_{L}\left(\right.$ arrow). The latency betwecn the fast CAP and the first spikes in $T_{J}$. and $P_{L}$ is indicated by $t_{l} . B$, When the $\mathrm{M}$ axon is fired during a quiet period between episodes of spontaneous activity, $\mathrm{M}$ cellevoked spikes in $T_{L}$ and $P_{L}$ are not seen, although the fast CAP in $V R 10_{L}$ (seen at higher gain than in $A$ ) remains. The small spike in the middle of the $T_{L}$ trace was not evoked by the $\mathrm{M}$ action potential, as evidenced by its absence following other firings of $M_{L}$ under the same conditions. $C$, Spikes recorded in $T_{L}$ and $P_{L}$ after stimulation of $V R 10_{L}$ with the en passant electrode (at artifact). Several sweeps are superimposed. The latencies of the first and last spikes in the nerves are indicated by $t_{2}$ and $t_{3}$, respectively. 
abruptly at the lesion site (Fig. $5 B$ ) even in cases where the operation consisted of a crush that allowed the two ends of the spinal cord to remain attached. (The location of the lesion usually could be recognized by a constriction of the cord or an irregularity in the shape of the central canal. However, in some tadpoles sacrificed at long postoperative times, the cord appeared normal and the site of damage was inferred from the morphology of the $\mathrm{M}$ axons; see below).

By 2 days, the proximal stump of the $M$ axon usually has retracted 1 or 2 segments from the site of damage, and a swelling, referred to as a "retraction bulb" by previous authors, has formed at the end of the axon (Fig. $6 A$ ). In some specimens, fine processes can be seen to emerge from the swelling, extending toward the lesion (Fig. 6A). Whether these represent regenerating sprouts or collaterals that were present at the time of the operation is not clear. In any event, regenerating sprouts definitely can be identified as early as 3 to 5 days after axotomy, since some preparations examined at this time have dye-filled processes arising from the proximal stump that cross the lesion and branch on the other side (Fig. $6 B$ ). Thus, anatomical regeneration is initiated early by these axons.

Progressive outgrowth of regenerating $M$ axons. Although there is a great deal of variability in the rate and form of $M$ axon regeneration from one preparation to the next, a gradual increase in the caudal extent of regenerating processes generally was observed in specimens of increasing postoperative age (compare Figs. $6, B$ and $C$, and 7 ). This is consistent with a mechanism of regeneration by continuous axonal outgrowth beginning at the proximal stump, rather than by fusion of the proximal and distal stumps of the original axon. If the latter mechanism obtained, a discontinuity should have been seen in the time course of the increasing caudal extent of dye-filled processes, corresponding to the time at which the two stumps fused. Such a discontinuity was not
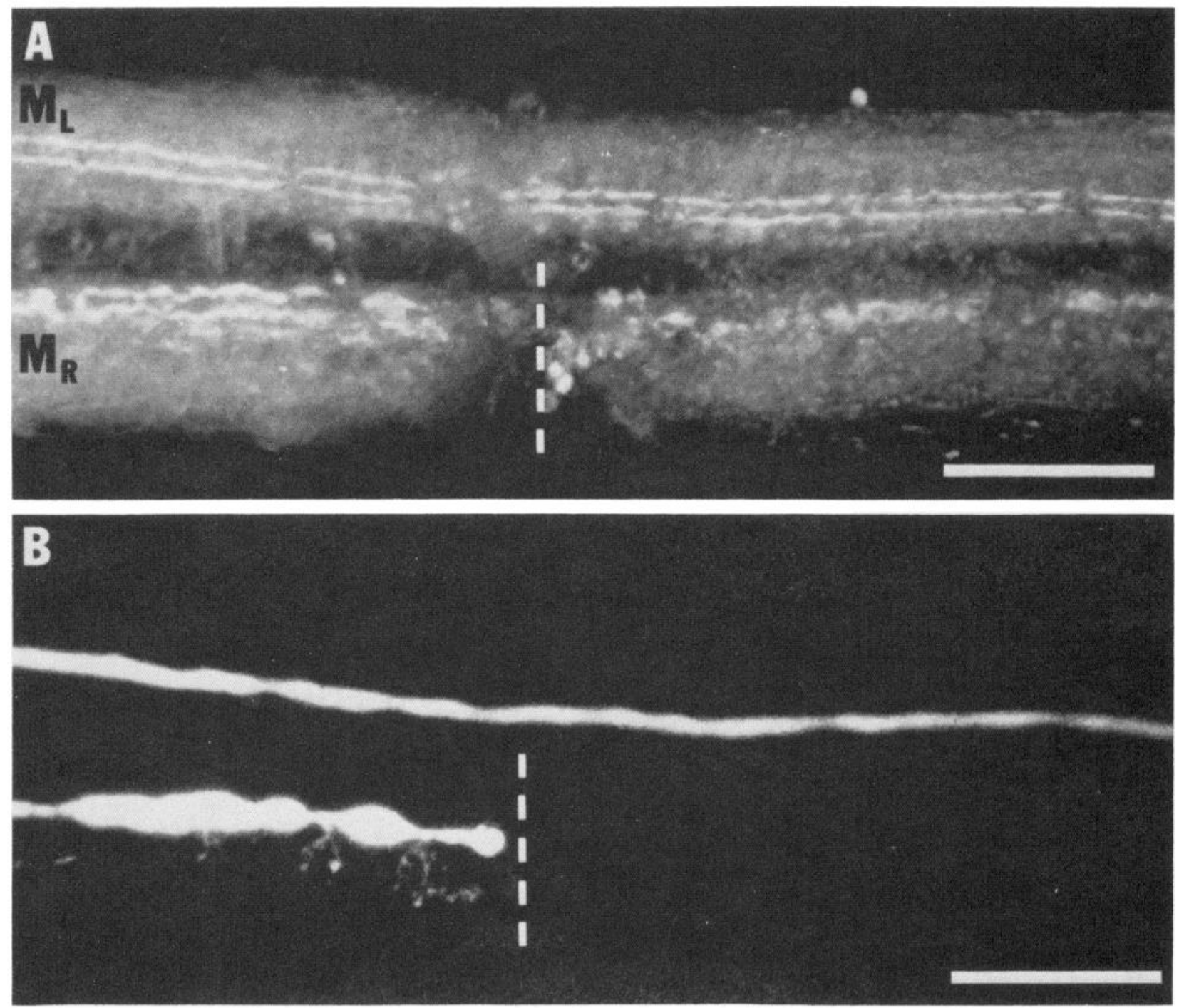

Figure 5. Short term responses of transected M axons. A, Part of a spinal cord transected 1 day earlier on its right side only, viewed between crossed polarizing filters. The tadpole was at stage 48 when the lesion was made. The sheath of the right $M$ axon is disrupted caudal to the lesion. $M_{L}$ and $M_{R}$, left and right $\mathrm{M}$ axons, respectively. $B$, Same region as in $A$, viewed with fluorescence optics after injecting both $\mathrm{M}$ axons with Lucifer Yellow rostral to the lesion. The dye in the right $\mathrm{M}$ axon stops abruptly at the lesion. In this and all succeeding anatomical figures, dashed lines denote the site of the lesion. Calibration bars, $100 \mu \mathrm{m}$. 

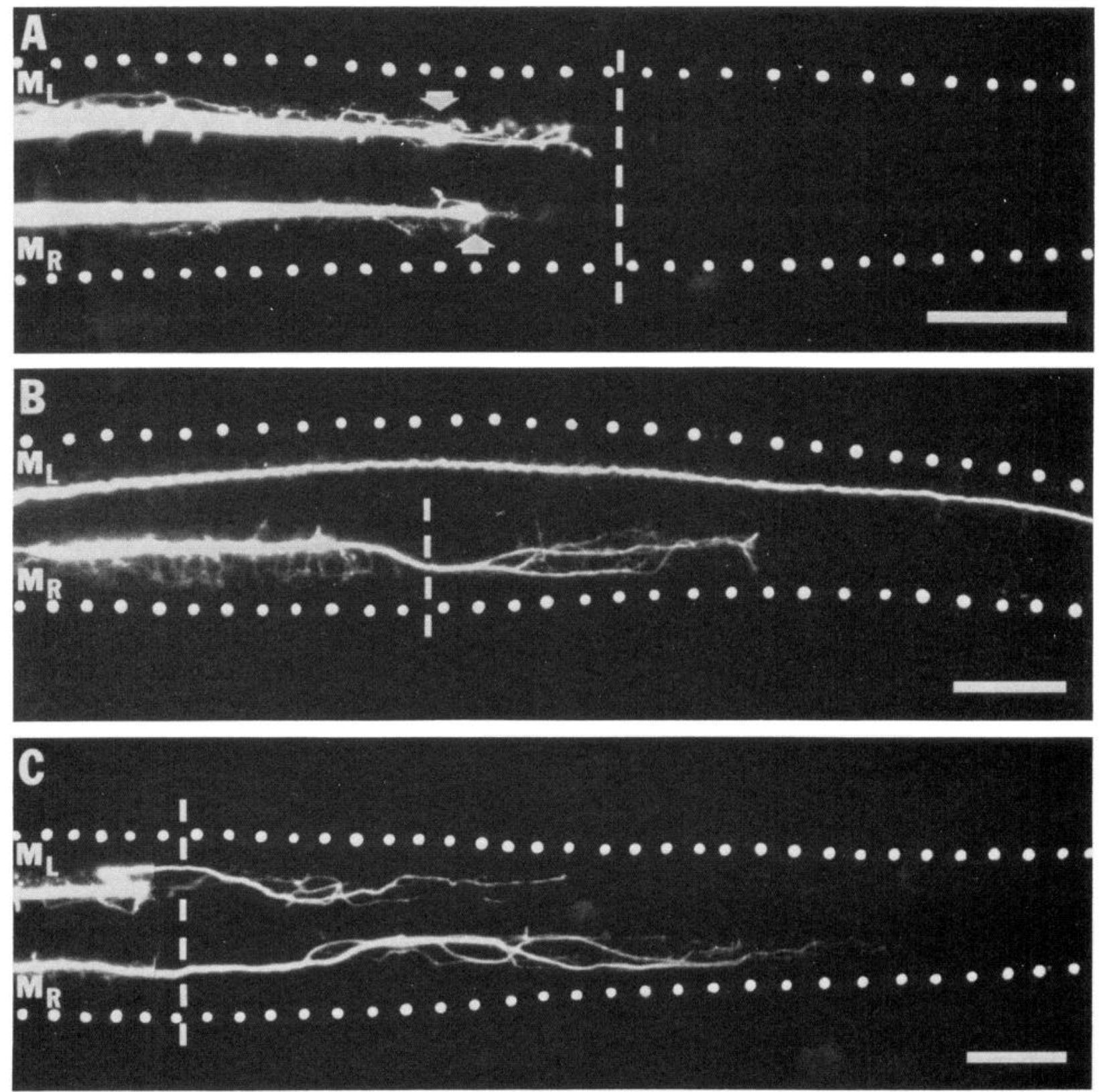

Figure 6. Progressive outgrowth of regenerating $\mathrm{M}$ axons. $A, B$, and $C$ show the $\mathrm{M}$ axons of 3 tadpoles that received spinal cord lesions at stage 48. A, Two days after both axons were transected, they have retracted from the lesion and formed swellings (arrows). Processes emerging from the swellings may have been present at the time of transection. $B$, Four days after the right side of the cord was crushed, the right $\mathrm{M}$ axon $\left(M_{R}\right)$ has produced a sprout that has grown nearly $300 \mu \mathrm{m}$ beyond the lesion. The left $\mathrm{M}$ axon $\left(M_{L}\right)$ was undamaged. $C$, Six days after both axons were transected, they send sprouts caudal to the lesion: $850 \mu \mathrm{m}$ for sprouts from the right $\mathrm{M}$ axon and almost $400 \mu \mathrm{m}$ for those from the left $\mathrm{M}$ axon. Calibration bars, $100 \mu \mathrm{m}$.

apparent. In addition, the morphology of regenerating $M$ axons argues against fusion as the mechanism by which regeneration occurs. Instead of one or more fine processes that span the lesion to connect two large, normal looking axonal segments, sprouts arise from the proximal stump and become finer and more highly branched as they grow caudally (Fig. 6C).

Tadpoles sacrificed several weeks after receiving spinal cord lesions may have regenerated $\mathrm{M}$ axons that extend far beyond the lesion (Fig. 7). In some cases, the maximum caudal extent of regeneration was impossible to determine accurately, due to high background fluores- cence and low dye concentration at large distances from the site of injection. Still, a total of 20 preparations were found in which one or both of the $\mathrm{M}$ axons had grown at least $2 \mathrm{~mm}$ caudal to the lesion; in 7 of these, $\mathrm{M}$ sprouts had grown $3 \mathrm{~mm}$ or more. Depending upon the stage of the tadpole at the time of sacrifice, these distances are equivalent to approximately 5 to 10 spinal segments. In 4 cases, this extensive caudal regeneration occurred during postoperative periods as short as 3 to 4 weeks.

Morphology of axotomy-induced sprouting. Processes that sprout from the $\mathrm{M}$ axon after transection and grow across the lesion usually arise directly from the retraction 
bulb (Figs. 6B and 11). Occasionally, sprouts originate from the proximal segment of the axon just rostral to the bulb (Fig. $6 C$ ). Within the lesion, sprouts may follow abnormal paths which send them toward the dorsal surface of the spinal cord; when this happens, they usually return to the ventral surface after reaching the caudal border of the lesion.

The typical picture of a regenerating $M$ axon consists of a single major process that crosses the lesion site and then branches extensively (Figs. $6 \dot{B}, 7$, and 11). In some tadpoles sacrificed at long postoperative times, this branching occurs several hundred micrometers caudal to the lesion, at the distal end of a major process which has only short collaterals along the rest of its length (Fig. 7). This observation is consistent with the hypothesis that the regenerating axon sends out several processes as it grows, one of which survives and increases in diameter, while the others are retracted. The morphology of the axons in Figure $6 C$ is also consistent with this hypothesis. The right $\mathbf{M}$ axon in that figure has one major process that begins branching about $100 \mu \mathrm{m}$ beyond the lesion; the left $M$ axon has several branches within the lesion itself, one of which is somewhat larger than the others. It is conceivable that the left $\mathbf{M}$ axon, which grew only half as far as the right, was in an earlier stage of regen- eration and that the smaller branches were undergoing retraction in favor of the larger.

This hypothesis cannot be proven conclusively by the methods used. Since each preparation was examined at only one time after the operation, it is impossible to know what the morphology of its $\mathrm{M}$ axons was before, or would have been after, the time of examination. A tadpole eventually resorbs its tail and caudal spinal cord during metamorphosis. Therefore, attempts to look for sprout retraction at very long postoperative times may be complicated by changes occurring in the cords of late metamorphic tadpoles. Moreover, examples were found of regenerating $\mathbf{M}$ axons with multiple long processes at relatively late times following axotomy (e.g., Fig. 8).

The presence of several long sprouts arising from the proximal stump is one example of the abnormal morphology displayed by some regenerating $\mathbf{M}$ axons. Even in cases where there is only one major process, that fiber may follow a much more tortuous path than that taken by normal axons (Fig. 7). Furthermore, axotomized M cells can send sprouts within the lesion to the contralateral side of the spinal cord, where they may grow caudally across the lesion or rostrally toward the brain (Fig. 8). Those that head in a rostral direction frequently turn around again and grow caudally; the same holds for axon

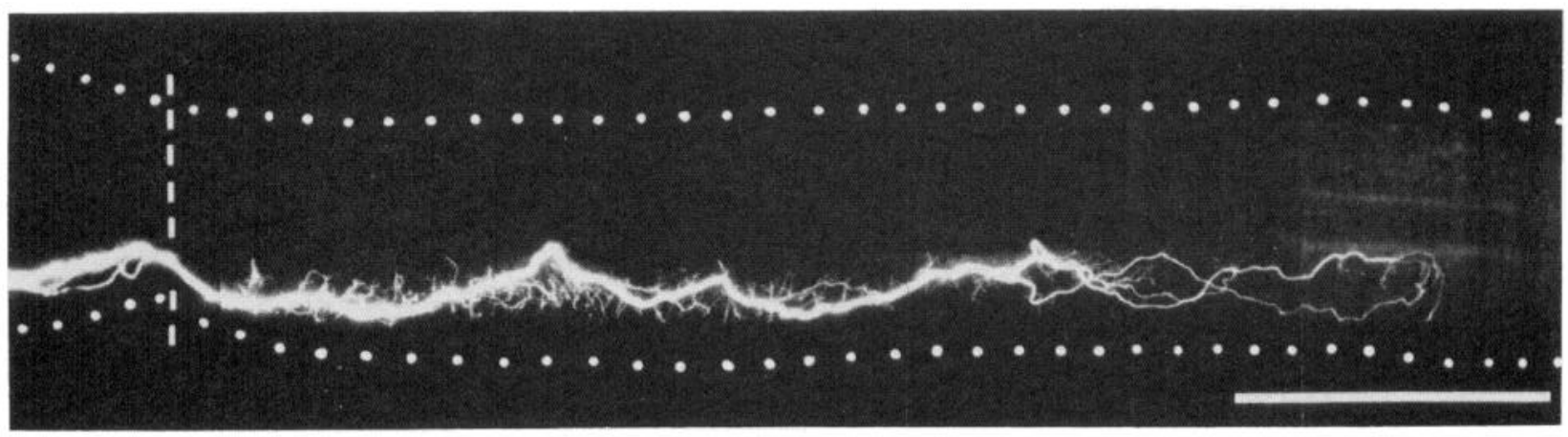

Figure 7. Long distance regeneration. The right $\mathrm{M}$ axon of a tadpole with a complete spinal transection 9 weeks earlier at stage 49 is shown. The total length of regeneration caudal to the lesion is $2 \mathrm{~mm}$; over the proximal $1.3 \mathrm{~mm}$ of this distance, the axon consists of one major process with short collaterals. The left $\mathrm{M}$ axon did not fill as far caudally as the lesion. Calibration bar, 500 $\mu \mathrm{m}$.

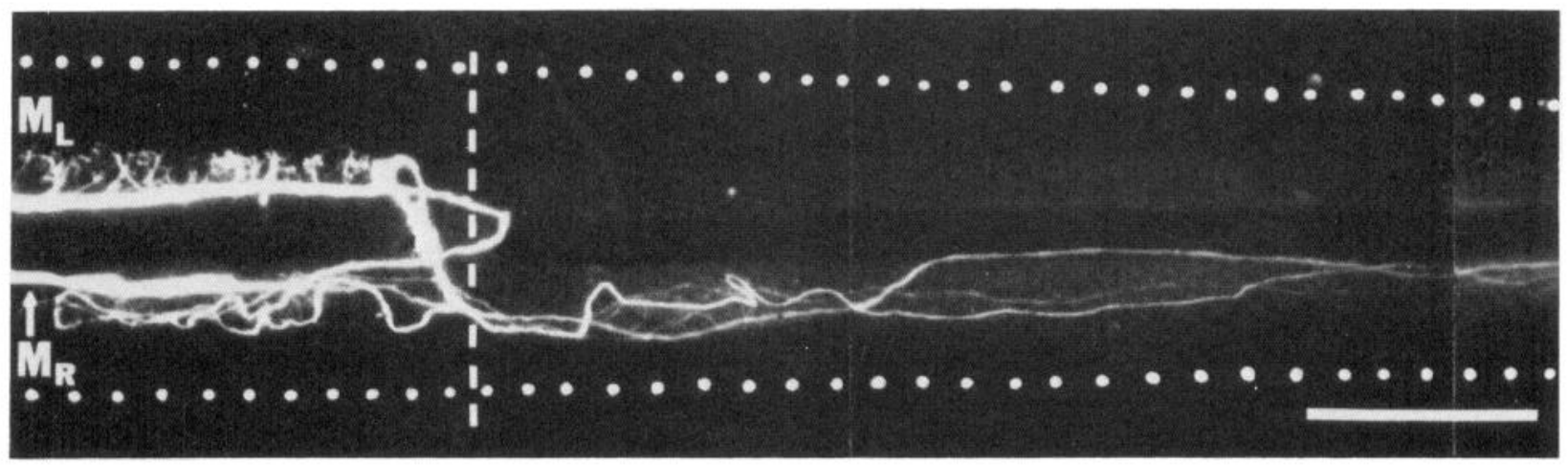

Figure 8. Abnormal morphology of transected $\mathrm{M}$ axons. M axons in a tadpole that received a complete spinal transection 6 weeks earlier at stage 46 . The left $\mathrm{M}$ axon $\left(M_{L}\right)$ produces three sprouts that cross to the right side of the cord at the lesion; on that side, one grows rostrally, one grows caudally, and one grows first rostrally and then caudally. The right $\mathrm{M}$ axon ( $\left.M_{R}\right)$ also sends a process caudal to the lesion on the right side. The full length of caudal growth is at least $2.2 \mathrm{~mm}$. Calibration bar, 200 $\mu \mathrm{m}$. 
sprouts that grow rostrally on their own side of the cord. $\mathrm{M}$ axons that produce multiple regenerative processes may send them in different directions, rostrally or caudally, on either side of the cord. On only two occasions were sprouts observed to cross to the opposite side of the cord after growing beyond the site of damage.

Frequency of anatomical regeneration caudal to the lesion. Lucifer Yellow was injected into one or both $\mathrm{M}$ axons in a total of 92 tadpoles that had received spinal cord lesions. (In 1 of the 93 examined, the $\mathbf{M}$ cells were studied physiologically but were not dye-injected successfully.) At least $1 \mathrm{M}$ axon had regenerated caudal to the lesion in 48 of 72 tadpoles $(67 \%)$ examined at postoperative times of more than 1 week and in 7 of $20(35 \%)$ examined after 1 week or less. The 20 tadpoles in the latter category include 4 that were tested after 0 to $24 \mathrm{hr}$. The 37 preparations without caudal $M$ axon regeneration include 11 in which the $M$ axons had grown within but not beyond the lesion and 7 in which the axons had grown rostrally.

Reactions of the $M$ axon myelin sheath. Within 1 day after axotomy, the myelin sheath begins showing signs of disruption caudal to the lesion, seen by examining the preparation between crossed polarizing filters (Fig. $5 A$ ). Distal sheath degeneration continues until, after 3 to 6 days, this method of examination no longer reveals any signs of the former sheath caudal to the lesion. $M$ axons that have regenerated following axotomy eventually become remyelinated as evidenced by the appearance of birefringent sheaths around the axons caudal to the lesion. In preparations where regenerating $M$ axons have multiple major sprouts, each of the sprouts may be ensheathed. Sheath re-formation has not been detected by this method earlier than 4 weeks after transection. However, the sensitivity of this assay may be too low to permil the detection of sheaths which are not yet fully formed or which surround sprouts of small diameter.

Re-formation of functional synapses caudal to the lesion. The ability of Xenopus $\mathrm{M}$ axons to regenerate functionally as well as anatomically was tested by impaling the axons rostral to the lesion and recording with suction electrodes on VRs caudal to the lesion. As shown in Figure 9, intracellularly evoked $M$ cell spikes can produce CAPs in caudal VRs. These fast CAPs have been recorded as far as 10 spinal segments caudal to the lesion and have latencies comparable to those seen in normal tadpoles $(\sim 2 \mathrm{msec}$ ), even in preparations where the $\mathrm{M}$ axons have regenerated multiple processes which are smaller in diameter than the proximal axon stump and are not visibly myelinated. Although these processes should have lower conduction velocities than the normal axon, the fact that fast CAPs in normal and cord-transected tadpoles have similar latencies suggests that the conduction velocity of the regenerated $M$ axons, even if reduced, still makes only a small contribution to the latency.

An alternative explanation is that the $\mathbf{M}$ axon itself does not synapse upon motor neurons with axons in the caudal VRs but instead synapses with some unidentified cell with a large, myelinated axon that contacts the motor neurons. Because fast CAPs are very probably due to a monosynaptic connection between the $M$ axon and motor
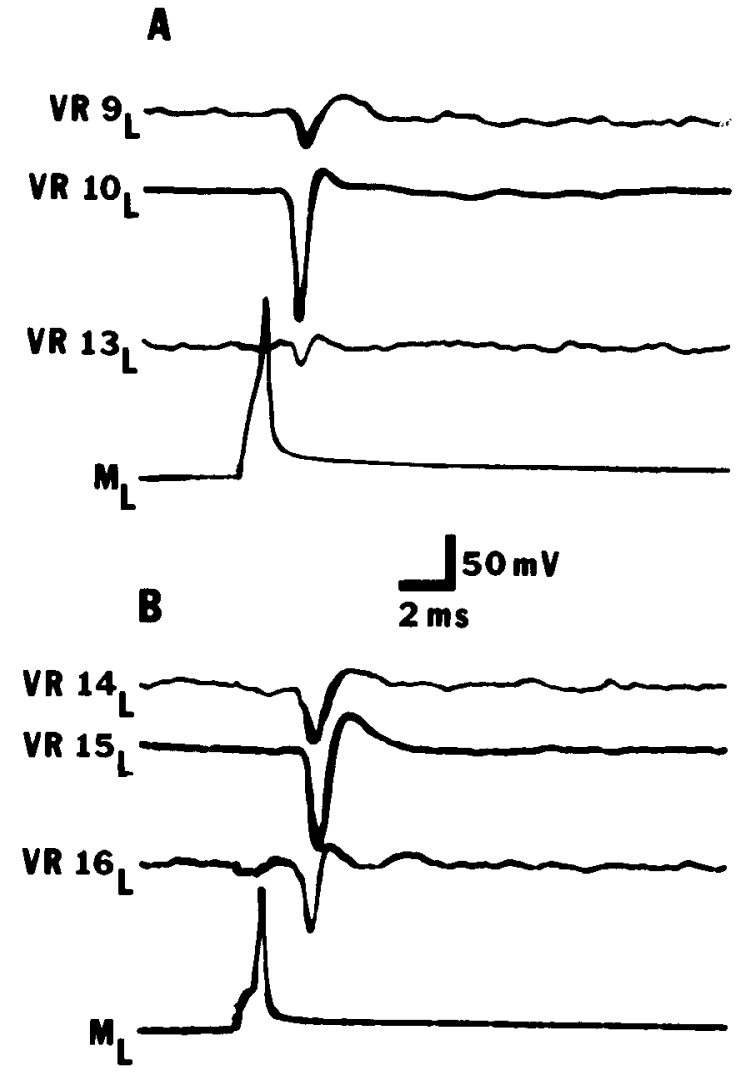

Figure 9. Functional reconnection of a regenerating $\mathrm{M}$ axon with motor neurons caudal to the lesion. $A$ and $B$, Suction electrode recordings from 6 left VRs in a tadpole that received a complete spinal transection 3 weeks and 4 days earlier at stage 46. The level of transection was near the point at which VR 7 exited the cord. Intracellular stimulation of the left $M$ axon $\left(M_{L}\right)$ produces fast CAPs in left VRs as far as 9 segments caudal to the lesion. Subsequent dye injection showed that this axon regenerated at least $2.2 \mathrm{~mm}$ beyond the lesion.

neurons (see above), one of these synapses would have to be electrical. This explanation is unlikely for two reasons. First, no other large, myelinated axons running parallel to the long axis of the cord are detectable in the spinal cords of normal tadpoles. In tadpoles with spinal lesions, axons of this description were found in the cord caudal to the lesion only when the $M$ axons themselves had regenerated and been remyelinated. Second, in every preparation, there was a good correlation between the physiological detection of fast CAPs in caudal VRs and the anatomical observation of axonal regeneration (e.g., Figs. 10 and 11). Never were fast CAPs recorded in VRs of segments beyond the maximal caudal extent of $M$ axon regrowth. Furthermore, as described above, axotomized $M$ cells occasionally regenerate processes that cross to the contralateral side of the cord at the lesion and grow caudally on that side. When this happens, the regenerating axon can form functional synapses with contralateral motor neurons (Fig. 12). A large, fast CAP in a caudal VR contralateral to the stimulated $M$ axon was found only in preparations in which that axon sent a process beyond the lesion on the contralateral side of the cord. 
A
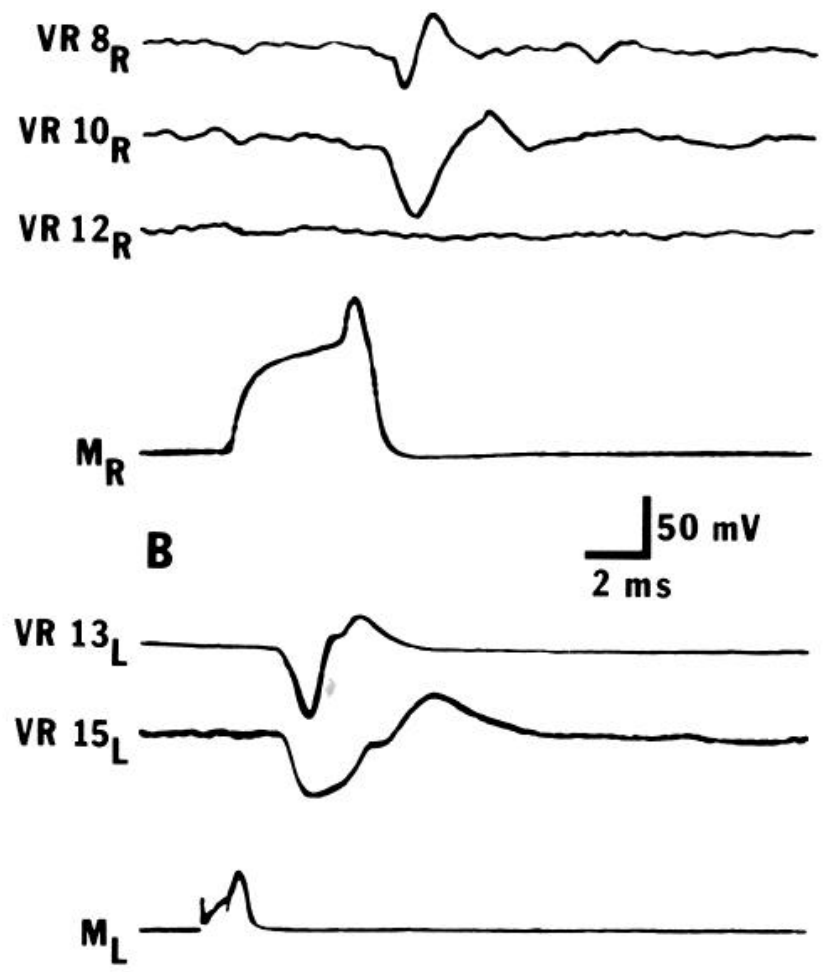

Figure 10. Functional reconnection 9 days after axotomy. $A$, Suction electrode recordings from right VRs 8,10 , and 12 , in a tadpole that had the right side of its spinal cord transected 1 week and 2 days earlier at stage 49 . An action potential in the right $\mathrm{M}$ axon $\left(M_{R}\right.$; arising atop a large depolarization produced by a long current pulse) elicits fast CAPs in VRs 8 and 10. VR 8 came from the part of the cord near the lesion; therefore, the fast CAP recorded in it may not be due to regenerated synapses formed by the right $M$ axon. Fast CAPs seen in right VR 10 (and right VR 11, not shown) probably are due to regeneration. Fast CAPs were not observed in right VR 12 (or right VRs 13 , 14 , or 15 , not shown). $B$, The same preparation as in $A$. Stimulation of the left $\mathrm{M}$ axon $\left(M_{L}\right)$, undamaged by the previous operation, evokes fast CAPs recorded as far caudal as segment 15 . See Figure 11 for the anatomy of the $M$ axons in this preparation.
Therefore, the occurrence of fast CAPs in VRs caudal to the lesion, following stimulation of $\mathrm{M}$ axons rostral to the lesion, is taken as evidence that regenerating $M$ axons can establish synapses with motor neurons caudal to the lesion and that transmission through these synapses is capable of bringing the motor neurons to threshold.

Re-formation of synapses by regenerating $\mathrm{M}$ axons was observed as early as 9 days after spinal transection (Fig. 10). Thus, both process outgrowth and synaptic reconnection can take place rapidly in this system. In light of the correlation between the extent of functional reconnection and that of anatomical regeneration (Figs. 10 and 11), it appears that synapse formation may be occurring as the regenerating sprouts grow along the cord, within the limits of temporal resolution of these experiments.

The possibility of reinnervation of motor neurons by axotomized $M$ cells was examined in a total of 50 tadpoles, transected from stages 46 to 56 . In 27 of these $(54 \%)$, there was evidence that at least $1 \mathrm{M}$ axon had re-

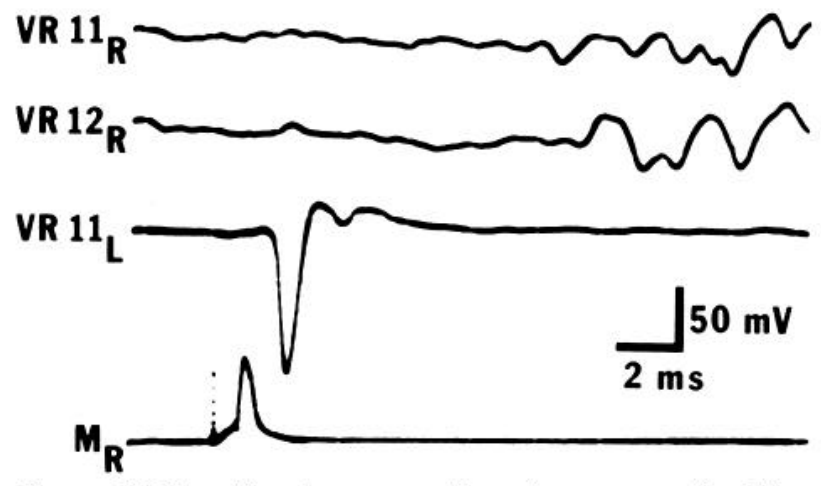

Figure 12. Functional reconnection of a regenerating $\mathrm{M}$ axon with contralateral motor neurons. Intracellular stimulation of the right $\mathrm{M}$ axon $\left(M_{R}\right)$ rostral to the lesion produces a fast CAP in VR 11 on the left side of the cord. Fast CAPs are absent in VRs 11 and 12 on the right side of the cord. The preparation is from a tadpole that received a complete spinal transection (at approximately the level at which VR 7 exited from the cord) 6 weeks and 2 days earlier at stage 46 . Subsequent dye injection into the right $\mathrm{M}$ axon showed that it crossed to the left side of the cord at the lesion and grew at least $2.1 \mathrm{~mm}$ caudal to the lesion on that side.

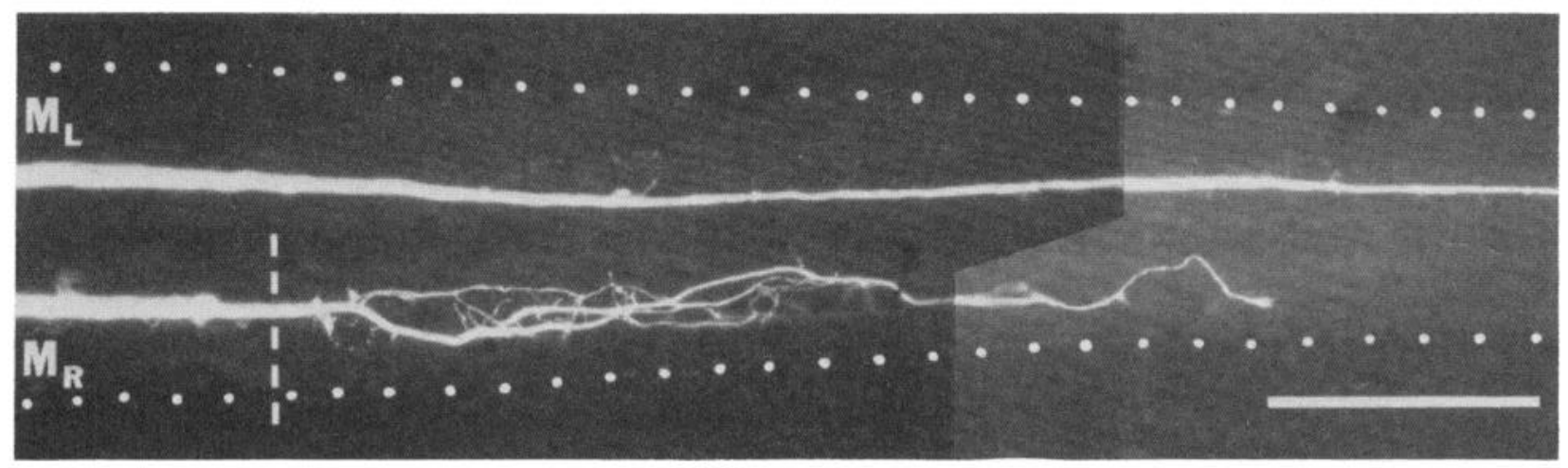

Figure 11. Anatomy of a regenerating $\mathrm{M}$ axon that has made a functional reconnection 9 days after axotomy. $\mathrm{M}$ axons are of the preparation described in Figure 10. The right M axon $\left(M_{R}\right)$ sends sprouts approximately $700 \mu \mathrm{m}$ (roughly equivalent to 3 spinal segments) caudal to the lesion. The left $\mathrm{M}$ axon $\left(M_{L}\right)$ was not damaged. Calibration bar, $200 \mu \mathrm{m}$. 
formed functional synaptic contacts with motor neurons caudal to the lesion. The actual percentage of individuals with re-formed synapses between $M$ axons and motor neurons is probably higher than this for the following reasons.

(a) In some preparations, only $1 \mathrm{M}$ axon was impaled successfully, and it did not regenerate beyond the lesion. The axon that was not tested could have regenerated and established contacts.

(b) Sometimes recordings were made only from VRs caudal to the maximal extent of $\mathrm{M}$ axon sprouting, determined later by dye injection. Recordings from more proximal VRs might have revealed synaptic connectivity in those segments.

(c) The failure to record $\mathbf{M}$ cell-evoked fast CAPs from particular VRs does not prove the absence of synapses between the $M$ axon and motor neurons in those segments, since some VRs show no sign of $\mathrm{M}$ cell input even in normal tadpoles (see above).

Specificity of synapse re-formation by regenerating $M$ axons. The ability of $M$ cell spikes to elicit fast CAPs in VRs caudal to a spinal lesion, especially in those from nonlumbar segments, indicates that regenerating $M$ axons can reinnervate the appropriate class of motor neurons, namely, primary motor neurons. Since individual motor neurons are not identifiable, it cannot be determined if regrowing $M$ axons synapse with the same individual cells that received $M$ synapses before the lesion was made. Therefore, the specificity of synaptic reconnection, that is, the formation of synapses on appropriate targets at the exclusion of inappropriate targets, can be examined only for paticular groups of potential postsynaptic cells.

It was shown above that $M$ cells in normal Xenopus tadpoles do not synapse upon those ventral horn motor neurons with the largest, fastest conducting axons in the tibial or peroneal nerve of the hindlimb. In order to ascertain whether regenerating $M$ axons can exhibit the same kind of discrimination during reinnervation, the experimental test used on normal tadpoles was used on tadpoles that had received spinal transections several weeks earlier.

For these experiments, the lesions were made near the level at which the 5th and 6th VRs exit the spinal cord, well rostral to the lumbar segments of the cord, in tadpoles at stage 49 or older. Lamb (1974) has reported that some motor neurons have axons in the hindlimb bud as early as stage 50, shortly after these neurons appear in the ventral horn. Therefore, stage 49 is probably the earliest stage at which $M$ axons have access to both primary and ventral horn motor neurons. To test for specific reinnervation (with respect to these two classes of neurons) in tadpoles transected prior to stage 49 would be to ask whether the axotomized $M$ cell could make correct choices among potential postsynaptic targets that it was not required to make before axotomy.

Tests for specificity of synapse re-formation were performed on 13 regenerating $\mathbf{M}$ axons in 10 tadpoles at stages 55 to 57 .

In 8 of these tadpoles ( 7 of them transected at stage 49 and 1 at stage 53), the synaptic specificity of the regenerating $M$ axons was very similar to that of normal $M$ axons (e.g., Fig. 13A). Recordings were made from 21 tibial and peroneal nerves for $11 \mathrm{M}$ axons between 4 and 15 weeks after transection. For all 21 nerves, $t_{l}$, the minimum latency between the fast CAP in VR 9 or 10 and the first spikes in the limb nerves, was longer than $t_{2}$, the conduction time of the fastest motor axons of these nerves, but for only 6 of the 21 was $t_{I}$ longer than $t_{3}$, the conduction time of the slowest motor axons. Therefore, like normal $M$ axons, these regenerating $M$ axons appeared not to synapse with tibial or peroneal motor neurons with the fastest conducting axons. The same

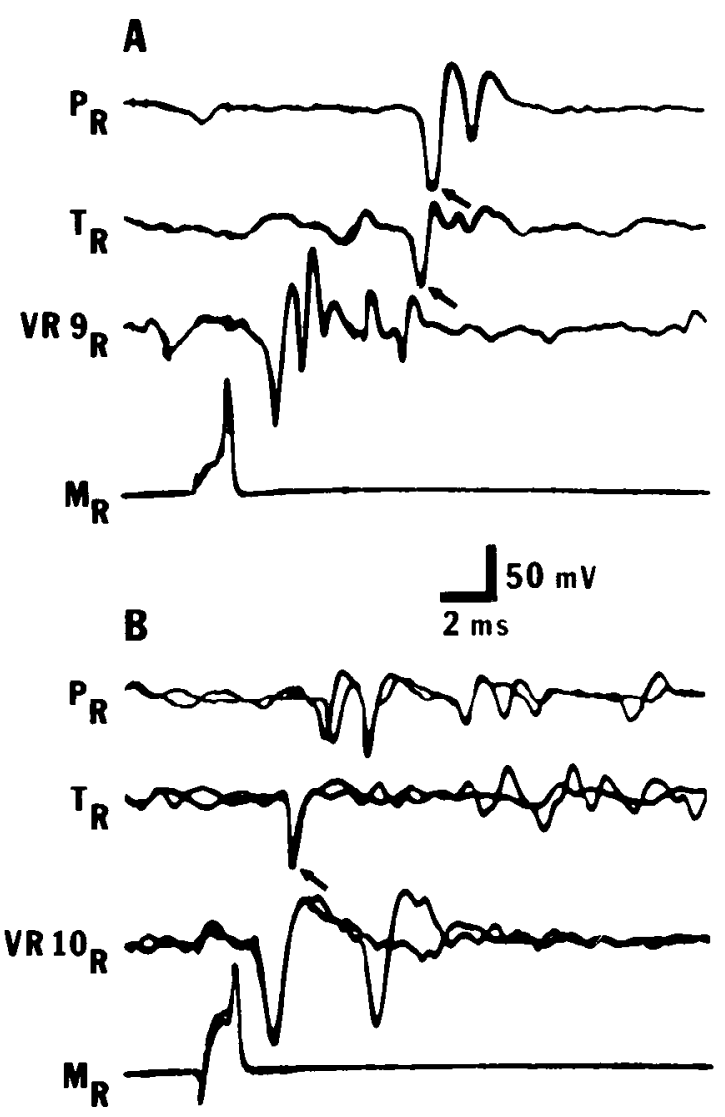

Figure 13. Tests for specificity of input to spinal motor neurons by regenerating $\mathrm{M}$ axons. $A$, An action potential in the right $\mathrm{M}$ axon $\left(M_{R}\right)$ elicits a fast CAP in right $\operatorname{VR} 9\left(V R 9_{k}\right)$; spikes (at arrows) in the right tibial $\left(T_{R}\right)$ and peroneal $\left(P_{R}\right)$ nerves follow the fast CAP with a latency of approximately 5 msec. When $V R 9_{K}$ was stimulated (not shown), the first spikes arrived in $T_{R}$ and $P_{K}$ with a latency of 1.0 to $1.2 \mathrm{msec}$. Thus, this regenerating $M$ axon appears not to have synapsed upon fast motor neurons of $T_{R}$ or $P_{k}$, showing the same specificity as a normal $M$ axon. The spinal cord of this tadpole had been transected 15 weeks earlier at stage $49 . B$, In another tadpole, stimulation of the right $\mathrm{M}$ axon produces a fast CAP in right VR $10\left(V R 10_{R}\right)$. Two sweeps are superimposed. Activity in $P_{k}$ follows with a latency slightly greater than that expected for the fastest axons in $P_{k}$. However, the first spike in $T_{R}$ (arrow) occurs approximately $0.7 \mathrm{msec}$ after the fast CAP, at a time expected for spikes of the fastest conducting axons in that nerve. Therefore, this $M$ axon appears to have re-established synapses with less specificity than a normal $M$ axon. This tadpole received a spinal lesion 14 weeks and 4 days earlier, at stage 49 . In $A$ and $B$, Ringer's solution contained $5 \mathrm{~mm}$ glucose and $20 \mathrm{mg}$ /liter of $d$-tubocurarine chloride. 
uncertainty regarding $\mathrm{M}$ input to the slower conducting motor axons of these nerves exists for both normal and regenerating $\mathrm{M}$ axons.

In the remaining 2 tadpoles ( 2 regenerating $\mathbf{M}$ axons, both transected at stage 49), $t_{1}$ was equal to $t_{2}$ for 3 of the 4 nerves tested (e.g., Fig. 13B). This suggests that these $2 \mathrm{M}$ axons formed synapses on inappropriate targets, namely, tibial and/or peroneal motor neurons with fastconducting axons. These tadpoles were examined after postoperative periods of 6 and $14 \frac{1}{2}$ weeks, within the range of periods for the other 8 tadpoles.

\section{TABLE I}

Stage dependence of $M$ axon regeneration

The fraction of tadpoles showing anatomical regeneration and functional reconnection of axotomized $\mathrm{M}$ cells, arranged according to the stage of the tadpoles at the time of the spinal lesion. Anatomical regeneration means that at least 1 of the $M$ cells sent a process caudal to the lesion. Functional reconnection means that at least 1 of the $\mathrm{M}$ axons, when fired rostral to the lesion, evoked fast CAPs in a VR caudal to the lesion. Preparations in which neither $M$ axon was impaled successfully and preparations examined at postoperative times of 1 week or less are not included.

\begin{tabular}{ccc}
\hline Stage at Lesion & $\begin{array}{c}\text { Anatomical } \\
\text { Regeneration }\end{array}$ & $\begin{array}{c}\text { Functional } \\
\text { Reconnection }\end{array}$ \\
\hline 39 & $0 / 1$ & \\
40 & $0 / 1$ & \\
41 & $1 / 1$ & \\
42 & $0 / 1$ & \\
43 & & \\
44 & $1 / 2$ & \\
45 & $2 / 3$ & $7 / 8$ \\
46 & $10 / 11$ & $1 / 1$ \\
47 & $2 / 2$ & $2 / 2$ \\
$47 / 48$ & $3 / 3$ & \\
48 & $1 / 1$ & $15 / 26$ \\
49 & $22 / 30$ & \\
50 & $0 / 1$ & $0 / 1$ \\
51 & $1 / 1$ & $0 / 2$ \\
52 & $1 / 2$ & $1 / 2$ \\
53 & $1 / 3$ & $0 / 2$ \\
54 & $0 / 2$ & $1 / 4$ \\
55 & $2 / 4$ & $0 / 2$ \\
56 & $1 / 3$ & \\
& & $27 / 50$ \\
\hline
\end{tabular}

Stage dependence of $M$ axon regeneration. The ability of Xenopus $\mathrm{M}$ axons to regenerate has been demonstrated after spinal lesions performed at almost every stage covered in this study (Table I). The few exceptions are stages in which only 1 or 2 tadpoles were examined. Most significant is the fact that regeneration can occur even after transection at the latest stages, including stage 56 (Fig. 14). In addition, physiological evidence for functional synaptic reconnection was obtained in 1 tadpole whose cord was transected at stage 55 . Functional reconnection may have been present following lesions at stage 56 as well but could have gone undetected for some of the reasons detailed above. In any event, it is clear that the $\mathrm{M}$ axons do not lose the capacity to regenerate over this period in the tadpole's development.

Whether these axons experience a gradual reduction in regenerative ability is more difficult to answer. Of the 26 tadpoles given spinal lesions from stages 39 to 48,20 (77\%) had regrown at least $1 \mathrm{M}$ axon across the lesion (Table I). After lesions at stages 49 to 56,28 of $46(61 \%)$ had done so. This is not a dramatic change, particularly with such small numbers for many of the stages and with the great variability in the form and extent of sprouting shown by particular individuals at each stage.

Nevertheless, there are indications of a difference in the morphology of $\mathrm{M}$ axons transected in tadpoles at early and late stages. Axons in the latter category (especially after stage 53) typically display large, bulbous endings rostral to the lesion or regenerated processes that arise from a much thicker proximal stump (Fig. 14). Axons in the former category (especially before stage 50), examined at comparable or even shorter postoperative times, generally have lost their retraction bulbs and formed sprouts whose diameter more closely matches that of the proximal stump (Fig. 7). It is not clear whether this difference represents a stage-dependent change in the final response of the axotomized neuron or a decrease in its rate of regeneration in older tadpoles.

\section{Discussion}

\section{Normal $M$ axons}

Anatomy. The M axons in Xenopus tadpoles have at least two features that have not been reported previously

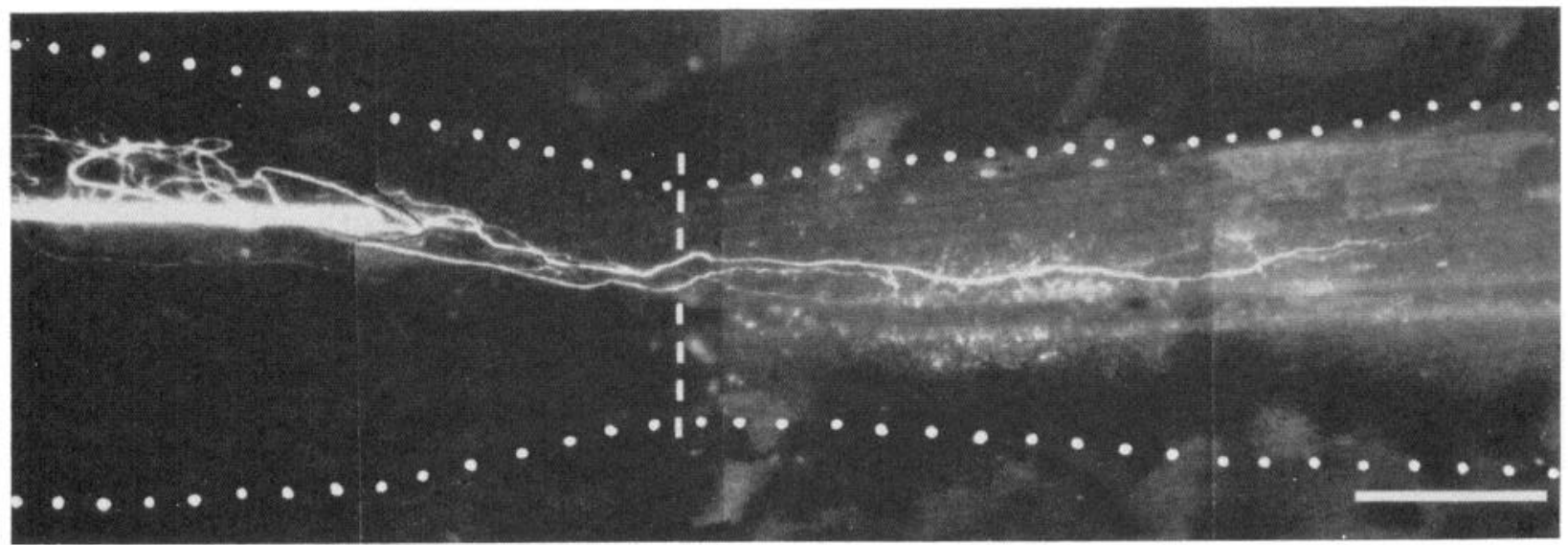

Figure 14. $\mathrm{M}$ axon regeneration following spinal transection at stage 56 . The left $\mathrm{M}$ axon of a tadpole with a complete spinal transection at stage 56, 7 weeks and 2 days earlier is shown. The axon sends two sprouts across the lesion, the longest of which extends nearly $800 \mu \mathrm{m}$ caudal to the lesion. The right $\mathrm{M}$ axon was not injected. Calibration bar, $200 \mu \mathrm{m}$. 
for $M$ axons of other species. One of these features is the presence of nodes in the myelin sheath around the axon; $\mathrm{M}$ axons in other species are myelinated but lack demonstrable nodes (Leghissa, 1956; Celio, 1976). Their close but irregular spacing differs from that for nodes of Ranvier in frog peripheral nerve axons; according to the formula of Tasaki (1953), a peripheral axon with a $10-\mu \mathrm{m}$ diameter should have an internodal length of about 1.5 $\mathrm{mm}$. However, examples of frog peripheral axons with short and variable internodal lengths have been noted (Stämpfli and Hille, 1976).

The other exceptional feature of Xenopus $\mathrm{M}$ axons is their extensive collateral arborization in both the medulla and spinal cord. The short axonal processes characteristic of $\mathrm{M}$ axons in other species (Faber and Korn, 1978) are in contrast to the long, highly branched, dorsolateral collaterals reported here. Two major collaterals, those that project into the forebrain and those that branch in the area of the opposite $\mathrm{M}$ soma, were described in Xenopus by Hibbard (1967). A medullary collateral associated with the contralateral M soma also has been found in the bullhead (Retzlaff and Fontaine, 1960).

Physiology. Spikes in an M axon produce postsynaptic potentials in ipsilateral motor neurons with a latency of $1 \mathrm{msec}$ or less, strongly suggesting a direct, chemical synapse from the $\mathrm{M}$ axon onto the motor neuron. However, other tests for monosynapticity were not conducted, and the possibility of a small electrical component is not eliminated. A direct connection between the $\mathbf{M}$ axon and ipsilateral motor neurons and the small contralateral response that is seen occasionally in Xenopus tadpoles also have been reported in teleosts (Diamond, 1971).

It would be interesting to know the location of the synapses between the $M$ axon and the ipsilateral motor neurons that it excites. The fact that postsynaptic potentials can be recorded in the motor axon means that the site of impalement in the axon is close to the synapse electrically. This is consistent with the hypothesis that the synapse is axoaxonic and that transmission occurs via some of the collaterals of the $M$ axon and the short, laterally directed processes of the motor axon. Such a synaptic arrangement has already been demonstrated for $M$ cells in teleosts and urodeles (Faber and Korn, 1978). In Xenopus, the extensive overlap between the long $M$ axon collaterals and the dendrites of postsynaptic motor neurons presents the additional possibility that the synapse may be axodendritic.

Over the stages cxamined, Xenopus $\mathrm{M}$ axons do not appear to provide direct synaptic input to motor neurons with the fastest conducting axons in the tibial or peroneal nerve. Yet, the $\mathbf{M}$ axon does provide input to primary motor neurons at these stages, indicating some specificity in $\mathrm{M}$ cell connections to motor neurons. The recording method used does not disprove the existence of direct synapses from the $M$ axon onto fast motor neurons of these nerves, if these synapses are subthreshold. However, firing the $M$ axon during episodes of spontaneous activity, a technique that sometimes allows otherwise undetectable connectivity to be revealed, was unsuccessful in revealing any such synapses.

$\mathrm{M}$ action potentials do elicit relatively long latency spikes in the tibial and peroneal nerves. Although the latency of these spikes in all cases was too long to be accounted for by activity in the fastest motor axons, in most instances, it was equal to that expected for activity in the slower motor axons. However, it was not possible with these experiments to distinguish a monosynaptic connection between the $M$ axon and a slow motor axon from a polysynaptic connection between the $M$ axon and a fast motor axon.

It should be emphasized that this test of the specificity of $\mathbf{M}$ cell input was conducted over a rather narrow range of stages. These experiments were not done on tadpoles at stages earlier than $54 / 55$, because the hindlimb nerves proved to be too small to record from prior to this stage. It is conceivable that the $M$ axons could synapse on fast motor neurons of the tibial and peroneal nerves over some period of development between stage 50, when the first motor axons reach the hindlimb bud, and stage $54 / 55$; they then might retract those synapses when functional transmission develops in the hindlimb. According to Hughes and Prestige (1967), the first movements in the hindlimb can be detected at stage 54 . Furthermore, stage 57 was the latest stage examined in these experiments. Although the tail of the tadpole begins to atrophy at stage 58, the $\mathrm{M}$ axons are still present in the unresorbed part of the spinal cord at least as late as slage 66 (Nieuwkoop and Faber, 1956). The changes occurring in the tadpole during the late stages of metamorphosis could include a change in the spinal synaptic connectivity of the $\mathrm{M}$ axons.

\section{Regenerating $M$ axons}

Spinal cord lesions were performed on Xenopus laevis tadpoles from stages 39 to 56. Muntz (1964) has reported that $\mathrm{M}$ axons are visible in Xenopus embryos as early as stage 28, and observations of Roberts and Clarke (1982) indicate that the axons have reached the spinal cord by stage $35 / 36$. Thus, the $M$ axons were present in the spinal cord when the lesion was made for most, and probably all, of the lesions performed in this study. Accordingly, the results reported here represent axonal regeneration of an axotomized neuron rather than the initial process outgrowth of a differentiating neuron.

Morphology of regeneration. The initial reactions of transected $M$ axons, the formation of retraction swellings and early process outgrowth, are features typical of severed axons in many animals, including snails (Murphy and Kater, 1980), other frog larvae (Lorenté de Nó, 1921), and mammals (Ramón y Cajal, 1959).

The evidence indicates that the regeneration of $M$ axons is due to progressive outgrowth beginning at the proximal stump rather than fusion or some other form of reconnection of the proximal and distal stumps. The latter mechanisms have been demonstrated for regenerating axons in some invertebrates (Hoy et al., 1967; Muller and Carbonetto, 1979; Birse and Bittner, 1981) but never for vertebrates (Jacobson, 1978). Furthermore, the tortuous paths taken by many regenerating $M$ axons suggest that they do not grow along any remnants of the distal stump that may remain following the lesion, as occurs in some regenerating central neurons of the leech (Muller and Carbonetto, 1979).

Regenerating $\mathrm{M}$ axons in Xenopus tadpoles may send one or more sprouts rostrally or caudally on either side of the cord. A similar observation has been reported for 
$M$ axons (and Müller axons) in the larval lamprey (Rovainen, 1976; Wood and Cohen, 1981). Although M axons can be traced a few millimeters past the lesion in both, there is an important difference between the caudal extent of regenerative growth of the $\mathrm{M}$ axons in the two animals. This distance can represent approximately 10 segments in Xenopus, while it is equivalent to only a couple of segments in the much larger lamprey. Therefore, in terms of the fraction of the total length of the cord occupied by the regenerating axons, regeneration of $M$ axons is much more limited in the larval lamprey. Wood and Cohen (1981) have suggested two possible reasons for this: $(\alpha)$ if neurons are restricted in their volume of cytoplasm or surface area of membrane (Devor and Schneider, 1975), profuse branching may act to eliminate further sprout extension and $(b)$ formation of synapses in the region of the lesion may inhibit caudal growil. However, neither of these explanations seems to hold for $\mathbf{M}$ axons in Xenopus tadpoles, since regenerated axons with multiple long sprouts have been observed and since these axons can re-form functional synapses near the lesion as well as far down the cord.

Functional reconnection. The return of short latency, $M$ cell-evoked fast CAPs in VRs caudal to the lesion and the good correlation between anatomical regeneration and the occurrence of fast CAPs strongly suggest that regenerating $M$ axons can re-establish functional synapses upon motor neurons caudal to the lesion.

It has not been established with certainty that fast CAPs evoked by stimulation of $M$ axons transected prior to stage 49 are, in fact, due to regenerated synapses, for the existence of synapses from the $M$ axon onto motor neurons in normal tadpoles is technically difficult to demonstrate earlier than stage 49. However, functional connectivity between $M$ cells and motor neurons probably begins much earlier than stage 49 , since, in the zebra fish, this connectivity develops in the embryo (Eaton et al., 1977). The last embryonic stage in Xenopus is stage 34/35 (Nieuwkoop and Faber, 1956).

Specificity of regeneration. In order for normal Mmediated behavior to return after a spinal lesion, it is necessary for the regrowing $M$ axons to distinguish appropriate from inappropriate targets during synapse reformation. The ability of regenerating $M$ axons to make this distinction was investigated with respect to two populations of neurons: primary motor neurons and ventral horn motor neurons with the fastest conducting axons in the tibial and peroneal nerves. This kind of experiment appears to be a good test of the competence of a regenerating $M$ axon to reinnervate specific targets. The axons and somata of both primary and ventral horn motor neurons are found in the ventral part of the spinal cord, although the somata tend to be grouped separately (Silver, 1942; Flanigan, 1960). Nevertheless, regenerating $M$ axons branch extensively and send sprouts into the regions of the cord occupied by both types of cells. In addition, motor neurons in both classes should be receptive to synapses from the $M$ axons, either because they were deafferented directly by the lesion or because they developed receptivity to synapses between the time of lesion and the time of examination.

In 11 of the 13 axons tested ( 8 tadpoles), there was no sign of direct $M$ input to motor neurons with fast con- ducting axons in the tibial or peroneal nerve, although the $M$ axons did synapse with primary motor neurons. Thus, these regenerating $M$ axons appeared to reinnervate motor neurons with the same degree of specificity shown by normal $M$ axons. The absence of short latency M-evoked spikes in the tibial and peroneal nerves of these 8 tadpoles does not eliminate the possibility that the $\mathrm{M}$ axons formed subthreshold synapses on fast motor neurons of those nerves. Although the presence of subthreshold synapses would indicate some lack of specificity at the level of synapse formation, reinnervation by the $M$ axons would still show specificity in terms of the functional output of the re-established circuitry.

In 2 of the $13 \mathrm{M}$ axons examined (2 tadpoles), spikes were recorded in the tibial and peroneal nerves after a delay consistent with the existence of direct $M$ input to fast motor neurons of those nerves. Thus, these $M$ axons apparently reinnervated with some degree of nonspecificity. Whether this is a transient phenomenon that characterizes only the initial stages of synapse formation could not be determined by the experiments performed, since each tadpole was examined at only one postoperative time. However, the postoperative survival periods of these 2 tadpoles were within the range of periods for the 8 tadpoles showing specific reinnervation.

Stage dependence of regeneration. The $\mathrm{M}$ axons retain the ability to regenerate anatomically and re-form functional synapses below the lesion over most of the stages in which these two phenomena were studied. Significantly, anatomical regeneration was found to occur within about 7 weeks after spinal transection at the latest stage examined (stage 56). This is the same stage for which Sims (1962) reported that Xenopus M axon regeneration does not occur, even after postoperative periods as long as 26 weeks. In both studies, the transections were performed at approximately the same rostrocaudal level of the cord. This discrepancy is most probably due to the different methods used to assay for regeneration in the two studies. The technique used by Sims (1962), involving examination of silver-stained, sectioned material, is not as sensitive a test for revealing the fine branching patterns of individual cells as is the examination of Lucifer Yellow-injected neurons in whole mount.

Although very few tadpoles were examined after spinal lesions performed at stages later than 49 , the ones that were studied seemed to display a difference in their response to axotomy. Many of the $M$ axons transected at later stages display retraction swellings, while most of those transected at earlier stages and examined after comparable postoperative times have lost their swellings and undergone extensive regeneration caudal to the lesion. Exceptions to this trend were seen, however. At present, it is not known how much of this difference is due simply to a change in the rate of regeneration, nor whether this difference arises from factors intrinsic or extrinsic to the $\mathrm{M}$ axon.

In conclusion, this investigation has provided evidence that Mauthner axons in Xenopus tadpoles can regenerate processes after they have been severed by a surgical lesion, and that these processes can grow across the lesion and re-form functional and often specific synaptic contacts with the axons' normal postsynaptic targets far beyond the location of spinal damage. Previous investi- 
gations have indicated that a return of normal function following spinal transection can be mediated by the formation of abnormal or nonselective synapses by the axotomized neurons (Bernstein and Gelderd, 1973; Selzer, 1978; Wood and Cohen, 1981). The present results suggest that a return of normal function in the transected vertebrate spinal cord also can be mediated by the direct reconnection of a regenerating neuron with its normal targets.

\section{References}

Baffoni, G. M. (1952) La rigenerazione della code e gli effetti reattivi dele cellule di Mauthner in anfibi anuri ed urodeli. Atti. Accad. Naz. Lincei Rc. 8: 189-194.

Bernstein, J. J., and J. B. Gelderd (1970) Regeneration of the long spinal tracts in the goldfish. Brain Res. 20: 33-38.

Bernstein, J. J., and J. B. Gelderd (1973) Synaptic reorganization following regeneration of goldfish spinal cord. Exp. Neurol. 4I: 402-410.

Birse, S. C., and G. D. Bittner (1981) Regeneration of carthworm giant axons following transection or ablation. J. Neurophysiol. 45: 724-742.

Björklund, A., and U. Stenevi (1979) Regeneration of monoaminergic and cholinergic neurons in the mammalian central nervous system. Physiol. Rev. 59: 62-100.

Celio, M. R. (1976) Die Schmidt-Lantermann'schen Einkerbungen der Myelinscheide des Mauthner-axons: Orte longitudinalen Myelinwachstums? Brain Res. 108: 221-235.

Devor, M., and G. E. Schneider (1975) Neuroanatomical plasticity: The principle of conservation of total axonal arborization. In Aspects of Neural Plasticity, F. Vital-Durand and M. Jeannerod, eds., pp. 191-200, Les Colloques de L'Institute National de la Santé et de la Recherche Médical, Paris.

Diamond, J. (1971) The Mauthner cell. In Fish Physiology, W. S. Hoar and D. J. Randall, eds., Vol. 5, pp. 265-346, Academic Press, New York.

Eaton, R. C., R. A. Bombardieri, and D. L. Meyer (1977) The Mauthner-initiated startle response in teleost fish. J. Exp. Biol. 66: 65-81.

Faber, D. S., and H. Korn (1978) Neurobiology of the Mauthner Cell, Raven Press, New York.

Flanigan, N. J. (1960) Experiments on the development of the mesial motor column in the frog. J. Comp. Neurol. 114: 67-77.

Gaupp, E. (1896) A. Ecker's und R. Wiedersheim's Anatomie des Frosches, Braunschweig, Vieweg.

Gurdon, J. B. (1967) African clawed frogs. In Methods in Developmental Biology, F. H. Wilt and N. K. Wessels, eds., pp. 75-84, Crowell Press, New York.

Hibbard, E. (1963) Regeneration in the severed spinal cord of chordate larvae of Petromyzon marinus. Exp. Neurol. 7: 175-185.

Hibbard, E. (1967) The ascending branch of Mauthner's axon in Xenopus: Its possible role in startle reflexes. Anat. Rec. 158: 251-256.

Holtzer, H. (1952) Reconstitution of the urodele spinal cord following unilateral ablation. II. Regeneration of the longitudinal tracts and ectopic synaptic unions of the Mauthner's fibers. J. Fixp. 7ool. 11.9: 263-301.

Hooker, D. (1925) Studies on regeneration in the spinal cord. III. Reestablishment of anatomical and physiological continuity after transection in frog tadpoles. J. Comp. Neurol. 38: 315-347.

Hooker, D. (1932) Spinal cord regeneration in the young rainbow fish, Lebistes reticulatus. J. Comp. Neurol. 56: 277-297.

Hoy, R. R., G. D. Bittner, and D. Kennedy (1967) Regeneration in crustacean motoneurons: Evidence for axonal fusion. Science 156: 251-252.
Hughes, A. (1959) Studies in embryonic and larval development in amphibia. II. The spinal motor-root. J. Embryol. Exp. Morphol. 7: 128-145.

Hughes, A., and M. C. Prestige (1967) Development of behaviour in the hind limb of Xenopus laevis. J. Zool. 152: 347-359.

Jacobson, M. (1978) Developmental Neurobiology, Plenum Press, New York.

Kalil, K., and T. Reh (1979) Regrowth of severed axons in the neonatal central nervous system: Establishment of normal connections. Science 205: 1158-1161.

Kiernan, J. A. (1979) Hypotheses concerned with axonal regeneration in the mammalian nervous system. Biol. Rev. 54: 155-197.

Lamb, A. H. (1974) The timing of the earliest motor innervation to the hind limb bud in the Xenopus tadpole. Brain Res. 67: $527-530$.

Lee, M. T. (1980) Anatomical regeneration and functional reconnection of an identified neuron in the CNS of a vertebrate. Soc. Neurosci. Abstr. 6: 386.

Leghissa, S. (1956) Contribution ultérieure à une meilleure connaissance de l'appareil de Mauthner chez les poissons et observations sur la morphologie de la fibre. Prog. Neurobiol. I. Neurochem. 2: 45-62.

Lorenté de Nó, R. (1921) La regeneración de la médula espinal en las larvas de batracio. Trab. Lab. Invest. Biol. Univ. Madr. 19: 147-183.

Michel, M. E., and P. J. Reier (1979) Axonal-ependymal asso ciations during early regeneration of the transected spinal cord in Xenopus laevis tadpoles. J. Neurocytol. 8: 529-548.

Muller, K. J., and S. Carbonetto (1979) 'The morphological and physiological properties of a regenerating synapse in the C.N.S. of the leech. J. Comp. Neurol. 185: 485-516.

Muntz, L. (1964) Neuro-muscular foundations of behavior in embryonic and larval stages of the anuran, Xenopus laevis. Doctoral dissertation, University of Bristol, Bristol, England

Murphy, A. D., and S. B. Kater (1980) Sprouting and functional regeneration of an identified neuron in Helisoma. Brain Res. 186: 251-272.

Nieuwkoop, P. D., and J. Faber (1956) Normal Table of Xenopus laevis (Daudin), North-Holland, Amsterdam.

Piatt, J. (1955) Regeneration of the spinal cord of the salamander. J. Exp. Zool. 129: 177-207.

Piatt, J., and M. Piatt (1958) Transection of the spinal cord in the adult frog. Anat. Rec. 131: 81-95.

Puchala, E., and W. F. Windle (1977) The possibility of structural and functional restitution after spinal cord injury. A review. Exp. Neurol. 55: 1-42.

Ramón y Cajal, S. (1959) Degeneration and Regeneration of the Nervous System, R. M. May, translator, Hafner Press, New York.

Retzlaff, E., and J. Fontaine (1960) Reciprocal inhibition as indicated by a differential staining reaction. Science 131: 104-105.

Roberts, A., and J. D. W. Clarke (1982) The neuroanatomy of an amphibian embryo spinal cord. Philos. Trans. R. Soc. Lond. (Biol.) 296: 195-212.

Rovainen, C. M. (1976) Regeneration of Müller and Mauthner axons after spinal transection in larval lampreys. J. Comp. Neurol. 168: 545-554.

Rovainen, C. M. (1979) Neurobiology of lampreys. Physiol. Rev. 59: 1007-1077.

Sechzer, J. A. (1974) Axonal regeneration or generation after corpus callosum section in the neonatal rat. Exp. Neurol. 45: 186-188.

Selzer, M. E. (1978) Mechanisms of functional recovery and regeneration after spinal cord transection in larval sea lamprey. J. Physiol. (Lond.) 277: 395-408.

Silver, M. L. (1942) The motoneurons of the spinal cord of the frog. J. Comp. Neurol. 77: 1-39. 
Sims, R. T. (1962) Transection of the spinal cord in developing Xenopus laevis. J. Embryol. Exp. Morphol. 10: 115-126.

Stämpfli, R., and B. Hille (1976) Electrophysiology of the peripheral myelinated nerve. In Frog Neurobiology, R. Llinás and W. Precht, eds., pp. 3-32, Springer-Verlag, New York.

Stefanelli, A. (1951) I fenomeni regenerativi e degenerative del midollo spinale caudale degli anfibi e dei rittili. Boll. Zool. 18: 279-290.

Tasaki, I. (1953) Nervous Transmission, Charles C Thomas, Springfield, IL.

Taylor, A. C. (1943) Development of the innervation pattern in the limb bud of the frog. Anat. Rec. 87: 379-413.
Tuge, H., and S. Hanzawa (1937) Physiological and morphological regeneration of the sectioned spinal cord in adult teleosts. J. Comp. Neurol. 67: 343-365.

Wood, M. R., and M. J. Cohen (1981) Synaptic regeneration and glial reactions in the transected spinal cord of the lamprey. J. Neurocytol. 10: 57-79.

Youngstrom, K. A. (1940) A primary and a secondary somatic motor innervation in Amblystoma. J. Comp. Neurol. 73: 139-151.

Zottoli, S. J. (1981) Regeneration following selective axotomy of an identified vertebrate central neuron. Soc. Neurosci. Abstr. 7: 259. 